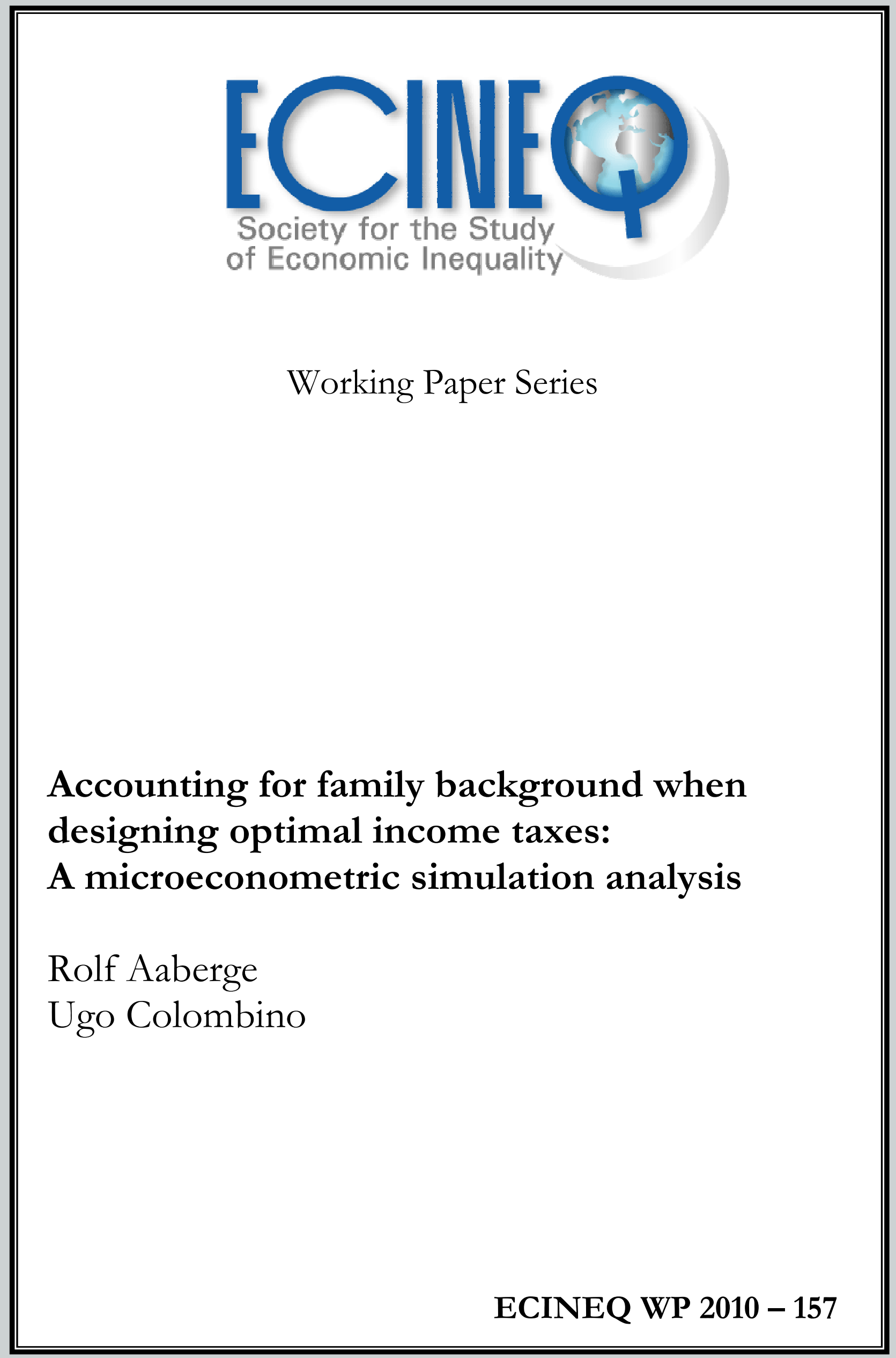




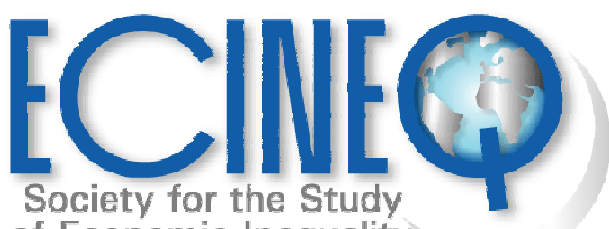

ECINEQ 2010-157

February 2010

of Economic Inequality

www.ecineq.org

\title{
Accounting for family background when designing optimal income taxes: A microeconometric simulation analysis*
}

\author{
Rolf Aaberge \\ Research Department, Statistics Norway \\ Ugo Colombino ${ }^{\dagger}$ \\ University of Turin
}

\begin{abstract}
The purpose of this paper is to introduce and adopt a generalised version of Roemer's (1998) Equality of Opportunity (EOp) framework, which we call extended EOp, for analysing second-best optimal income taxation. Unlike the pure EOp criterion of Roemer (1998) the extended EOp criterion allows for alternative weighting profiles in the treatment of income differentials between as well as within types when types are defined by circumstances that are beyond people's control. This study uses parental education as a measure of exogenous circumstances. An empirical microeconometric model of labour supply in Italy is employed to simulate and identify income tax-transfer rules that are optimal according to the extended EOp criterion. We look for second-best optimality, i.e. the tax-transfer rules are not allowed to depend on family background, they only depend on income: family background is taken indirectly into account. The rules are defined by a universal (not individualized) lump-sum transfer (positive or negative) and by one or two marginal tax rates. A rather striking result of the analysis is that the optimal tax-transfer rule turns out to be a universal lump-sum tax (with marginal tax rates equal to zero), under Roemer's pure EOp criterion as well as under the generalised EOp criterion with moderate degrees of aversion to within-type inequality. A higher degree of within-type inequality aversion instead produces EOp-optimal rules with positive marginal tax rates. When the EOp-version of the Gini welfare function is adopted, the optimal tax rule turns out to be close to the actual 1993 Italian tax system, if not for the important difference of prescribing a universal lump-sum positive transfer of 3,500,000 ITL (= 1807 Euros), which has no comparable counterpart in the actual system. On the other hand, when using the conventional equality of outcome $(\mathrm{EO})$ criterion, the pure lump-sum tax always turns out to be optimal, at least with respect to the classes of two- and threeparameter rules. We also compute optimal rules under the additional constraint that universal lump-sum taxes are not feasible. Overall, the results do not conform to the perhaps common expectation that the EO criterion is more supportive of "interventionist" (redistributive) policies than an extended EOp approach.
\end{abstract}

Keywords: Equality of opportunity, equality of outcome, labour supply, optimal income taxation.

JEL classification: D19, D63, H21, H24, H31.

\footnotetext{
${ }^{*}$ We would like to thank Tom Wennemo for skilful programming. Parts of this paper were written while Rolf Aaberge was visiting ICER in Torino. ICER is gratefully acknowledged for providing financial support and excellent working conditions. The Italian Ministry of University and Research (MURST, project MM13317213, 2000-2002) and the Norwegian Research Council have provided financial support for this project.
}

${ }^{\dagger}$ Address of correspondence: Department of Economics, Via Po 53, 10124, Turin, Italy, ugo.colombino@unito.it . 


\section{Introduction}

There is large research evidence regarding the impact of family background (e.g. parental education and/or income) on the economic success or, more generally, the level of well-being attained by the offspring. The hypotheses on the channels through which the effect takes place can vary, but the existence of the effect itself is well-established. ${ }^{1}$ In the terminology used in Roemer's theory of Equality of Opportunity (EOp) ${ }^{2}$, family background belongs to the category of the "circumstances", i.e. something beyond the individual's control. The EOp-criterion is interesting from the policy pointof-view, since the majority of citizens in most industrialised countries, although not unfavourable to redistribution, seem sensitive to the way a certain outcome has been attained. If the level of well-being attained by a given individual is seen as depending on her circumstances (such as family background) and her own effort, the policies inspired by the EOp criterion should account for the impact of the part of well-being attributable to circumstances (rather than to effort) on the distribution of well-being. In contrast, the policies inspired by the criterion of equality of achievement or Equality of Outcome (EO) should care about the distribution of well-being irrespective of whether is originated by circumstances or by effort. Although the EOp criterion does not necessarily imply less redistribution than the EO criterion, redistribution is more likely to receive support if it is designed to correct circumstances that are beyond people's control. On the other hand, if a bad outcome is associated with a lack of effort, redistribution is likely to be much less acceptable. In designing EOp-inspired mechanisms, besides direct interventions such as targeted income support, educational services etc. one can also consider indirect policies such as income taxation. In this paper we address the following question: What's the optimal income tax-transfer rule from the EOp perspective? More specifically, we present an empirical analysis of second-best optimal income taxation, adopting Equality of Opportunity (EOp) as the evaluation criterion.

The main purpose of this paper is to explore the implications of adopting the EOp criterion for the design of tax-transfer systems as compared to the EO criterion. A secondary purpose is to extend a previous contribution (Roemer et al. 2003), where the EOp criterion has been applied to evaluate the performance of current income tax rules in various countries, using a relatively simple common model of labour supply behaviour with calibrated parameters. The present paper extends the previous study in several respects.

\footnotetext{
${ }^{1}$ Behrman et al. (1999), Ermish and Francesconi (2002), Sacerdote (2002), Dustman (2004).

${ }^{2}$ Roemer (1998).
} 
First, instead of evaluating the current tax rules, we wish to determine the second-best optimal income tax rules (according to the EOp perspective). As in Mirrlees (1071), second-best optimality means that we limit ourselves to tax-transfer rules that depend only on income i.e. we assume that individual-specific lump-sum taxes are not feasible, nor can the tax-transfer rule depend on (observable) circumstances or "types". Our aim consists of identifying the tax-transfers rule that best conforms to the EOp criterion, assuming that the rule depends only on income. There are many examples in tax policy analysis or design where a similar second-best perspective in adopted. For example it is frequently asked whether the tax rule is more or less favourable to men rather than to women, to singles rather than to couples, to the young rather than to the elderly etc., even though the (actual or perspective) tax rule does not (directly) depend on those characteristics.

Second, we introduce an extended version of Roemer's (1998) pure EOp-criterion which can be considered as a combination of the pure EOp criterion and the more traditional Equality-ofOutcome (EO) criterion.

Third, we employ a relatively sophisticated model of labour supply that provides a simultaneous treatment of partners' decisions and accounts for quantity constraints on the distribution of hours.

Finally, while the analysis in Roemer et al. (2003) only concerned male heads of household 25-40 year old, this study deals with approximately the entire labour force. Whilst most tax evaluations are either based on representative agent models or micro-econometric models for single individuals or married females conditional on husbands' income, this study relies on models for both married couples and single individuals.

With respect to the traditional literature on optimal taxation, our contribution differs in two ways. First, while we share the same aim of identifying second-best tax-transfer rule, the social welfare function to be maximized is based on the EOp criterion instead of the EO criterion. Second, we solve the optimization problem computationally (i.e. by iteratively simulating a microeconometric model) rather than analytically. ${ }^{3}$

In Section 2 we briefly discuss the justification and definition of the EOp-criterion and its relationship to more traditional concepts of social welfare, where the concern focuses upon the equality of outcome (EO) criterion rather than equality of opportunity. In the same section we also introduce and motivate the extended EOp criterion.

In Section 3.1 we use a micro-econometric model of household labour supply, estimated on 1993 Italian data, to simulate the effects of various constant-revenue affine tax rules, i.e. the tax rules defined by a universal lump-sum transfer (positive or negative) and a constant marginal tax rate that

\footnotetext{
${ }^{3}$ The computational approach to designing optimal taxes is also adopted in Aaberge and Colombino (2008).
} 
produces the same revenue collected with the observed 1993 rule. These tax rules are evaluated and compared according to the extended EOp-criterion. Furthermore, the EOp-optimal tax rule is also identified. The model, the empirical specification, the data used and the estimates are illustrated in the Appendix. The main reason to perform the exercise with the affine tax rules is to make our results (obtained with a very detailed microeconometric model) comparable to those reported in Roemer et al. (2003) (obtained with a simple theoretical model and calibrated parameters). In fact, in Section 3.2 we perform a similar exercise as in Section 3.1, but looking at the class of tax-rules defined by a transfer and two tax rates (instead of one as for the affine rules). In Section 4 we compare the evaluation of tax rules according the EOp and EO criteria. Since it in many cases turn out that the optimal tax rule is a universal lump-sum tax, and since lump-sum taxes are typically judged hard to implement and to support politically, in Section 5 we provide optimal tax rules under the constraint that lump-sum taxes are not allowed. Section 6 summarises the main results. The Appendix illustrates the microeconometric model, the dataset used, the estimates and the the 1993 tax rule.

\section{The EO and EOp criteria}

The standard approach in evaluating tax systems is to employ a social objective (welfare) function as the basic evaluating instrument. This function is commonly used to summarise the changes in (adultequivalent) incomes resulting from introducing various alternatives to the actual tax system in a country. The simplest way to summarise the changes that take place is to add up the income differentials, implying that individuals are given equal welfare weights independently of whether they are poor or rich. However, if besides total welfare we also care about the distributional consequences of a tax system, then an alternative to the linear additive welfare function is required. In this paper we rely on the class of rank-dependent social welfare functions that originates from Mehran (1976) and are defined by

$$
W=\int_{0}^{1} p(t) F^{-1}(t) d t
$$

where $F^{-1}$ is the left inverse of the cumulative distribution function of (adult-equivalent) income $F$ with mean $\mu$ and $p(t)$ is a positive weight-function defined on the unit interval. As demonstrated by Yaari (1988) the social welfare functions (2.1) can be given a similar normative justification as is made for the "expected utility" social welfare functions introduced by Atkinson (1970). .

\footnotetext{
${ }^{4}$ Several other authors have discussed rationales for this approach, see e.g. Sen (1974), Hey and Lambert (1980), Donaldson and Weymark (1980, 1983), Weymark (1981), Ben Porath and Gilboa (1992) and Aaberge (2001).
} 
In this paper we use the following specification of $p(t)$,

$$
p_{k}(t)= \begin{cases}-\log t, & k=1 \\ \frac{k}{k-1}\left(1-t^{k-1}\right), & k=2,3, \ldots\end{cases}
$$

Note that the inequality aversion exhibited by the social welfare function $W_{k}$ associated with $p_{k}(t)$ decreases with increasing $k$. As $\mathrm{k} \rightarrow \infty, \mathrm{W}_{\mathrm{k}}$ approaches inequality neutrality and coincides with the linear additive welfare function defined by

$$
W_{\infty}=\int_{0}^{1} F^{-1}(t) d t=\mu
$$

It follows by straightforward calculations that $\mathrm{W}_{\mathrm{k}} \leq \mu$ for all $\mathrm{j}$ and that $W_{k}$ is equal to the mean $\mu$ for finite $k$ if and only if $F$ is the egalitarian distribution. Thus, $W_{k}$ can be interpreted as the equally distributed (equivalent) level of equivalent income. As recognised by Yaari (1988) this property suggests that $C_{k}$, defined by

$$
C_{k}=1-\frac{W_{k}}{\mu}, k=1,2, \ldots
$$

can be used as a summary measure of inequality ${ }^{5}$. Moreover, as was recognized by Ebert (1987) the justification of the social welfare function $W_{k}=\mu\left(1-C_{k}\right)$ can be made in terms of value judgement of the trade-off between the mean and (in)equality in the distribution of income. For a given sum of incomes the welfare functions $W_{k}$ take their maximum value when everyone receives the same income and may thus be interpreted as EO-criteria (equality of outcome) when employed as a measure for judging between tax systems.

Aaberge (2007) proves that the family of inequality measures $\left\{C_{k}: k=1,2, \ldots\right\}$ and the mean $\mu$ provide a complete characterization of the distribution function F. However, in applied work one has for practical reasons to restrict to a few measures of inequality. To this end, Aaberge (2007) draws on standard statistical practice to justify the use of $\mathrm{C}_{1}$ (the Bonferroni coefficient), $\mathrm{C}_{2}$ (the Gini coefficient) and $\mathrm{C}_{3}$ as a basis for summarizing the inequality information in an income distribution and the associated social welfare functions $W_{1}, W_{2}$ and $W_{3}$ to assess the trade-off between efficiency and

\footnotetext{
${ }^{5}$ As demonstrated by Aaberge (2001) $C_{k}$ - measures can also be axiomatically justified as criteria for ranking Lorenz curves.
} 
(in)equality. Moreover, these three measures of inequality also prove to supplement each other with regard to sensitivity to transfers at the lower, the central and the upper part of the income distribution. To ease the interpretation of the inequality aversion profiles exhibited by $W_{1}, W_{2}, W_{3}$ and $W_{\infty}$ Table 2.1 displays ratios of the corresponding weights - as defined by (2.2) - of the median individual and the 1 per cent poorest, the 5 per cent poorest, the 30 per cent poorest and the 5 per cent richest individual for different social welfare criteria. As can be observed from the weight profiles provided by Table $2.1 W_{1}$ will be particular sensitive to changes in policies that affect the welfare of the poor.

Table 2.1 . Distributional weight profiles of four different social welfare functions

\begin{tabular}{|lcccc|}
\hline & $\begin{array}{c}W_{1} \\
\text { (Bonferroni) }\end{array}$ & $\begin{array}{c}W_{2} \\
\text { (Gini) }\end{array}$ & $W_{3}$ & $\begin{array}{c}W_{\infty} \\
\text { (Utilitarian) }\end{array}$ \\
$\mathrm{p}(.01) / \mathrm{p}(.5)$ & 6.64 & 1.98 & 1,33 & 1 \\
$\mathrm{p}(.05) / \mathrm{p}(.5)$ & 4.32 & 1.90 & 1.33 & 1 \\
$\mathrm{p}(.30) / \mathrm{p}(.5)$ & 1.74 & 1.40 & 1.21 & 1 \\
$\mathrm{p}(.95) / \mathrm{p}(.5)$ & 0.07 & 0.10 & 0.13 & 1 \\
\hline
\end{tabular}

As indicated by Roemer (1998) using social welfare functions based on equality of outcome is controversial and might suffer from the drawback of receiving little support among citizens ${ }^{6}$. This is due to the fact that differences in outcomes resulting from differences in efforts are, by many, considered ethically acceptable and thus should not be the target of a redistribution policy. An egalitarian redistribution policy should instead seek to equalise those income differentials arising from factors beyond the control of the individual. Thus, not only the outcome, but its origin and how it was obtained, matters. This is the essential idea behind Roemer's (1998) theory of equality of opportunity, where people are supposed to differ with respect to circumstances, which are attributes of the environment of the individual that influence her earning potential, and which are "beyond her control". Roemer's theory has first and foremost been used as a basis for evaluating the impact of specific policies on distributions of income and education across types; see e.g. Roemer at al. (2003) ${ }^{7}$.

This study defines circumstances by family background (proxied by father's education), and classifies the individuals into three types according to father's years of education:

- less than 5 years (Type 1),

\footnotetext{
${ }^{6}$ See also Dworkin (1981a, 1981b), Arneson (1989, 1990), Cohen (1989) and Roemer (1993).

${ }^{7}$ We refer to Peragine (2002, 2004), Bourguignon et al. (2003) and Checchi and Peragine (2009) for discussions on how to measure (in)equality of opportunity.
} 
- 5-8 years (Type 2), and

- more than 8 years (Type 3).

Let $F_{j}^{-1}(t)$ denote the income level of the individual located at the $t^{\text {th }}$ quantile of the income distribution $\left(F_{j}\right)$ of type $\mathrm{j}$. The differences in incomes within each type are assumed to be due to different degrees of effort for which the individual is to be held responsible, whereas income differences that may be traced back to family background are considered to be beyond the control of the individual. As indicated by Roemer (1998) this suggests that we may measure a person's effort by the quantile of the income distribution where he is located. Next, Roemer declares that two individuals of different type have expended the same degree of effort if they have identical position (rank) in the income distribution of their type; i.e. an individual of type $i$ with income $\mathrm{F}_{\mathrm{i}}^{-1}(\mathrm{t})$ and an individual of type $j$ with income $\mathrm{F}_{\mathrm{j}}^{-1}(\mathrm{t})$ are supposed to expend the same degree of effort, which means that an EOp welfare function should aim at reducing the difference between this incomes. Thus, an EOp (Equality of Opportunity) tax policy should aim at designing a tax system such that $\min _{\mathrm{j}}^{-1}(\mathrm{t})$ is maximised for each quantile $t$. However, since this criterion is rather demanding and in most cases will not produce a complete ordering of the tax systems under consideration a weaker ranking criterion is required. To this end Roemer (1998) proposes to employ as the social objective the average of the lowest income at each quantile,

$$
\tilde{W}_{\infty}=\int_{0}^{1} \min _{j} F_{j}^{-1}(t) d t
$$

Thus, $\tilde{\mathrm{W}}_{\infty}$ ignores income differences within the most disadvantaged group and is solely concerned about differences that arise from the observed differential circumstances. By contrast, the EO criteria defined by (2.1) does not distinguish between the different sources that contribute to income inequality. As an alternative to (2.1) and (2.7) we introduce the following family of extended EOp welfare functions,

$$
\tilde{W}_{k}=\int_{0}^{1} p_{k}(t) \min _{j} F_{j}^{-1}(t) d t, k=1,2, \ldots
$$

where $p_{k}(t)$ is defined by (2.2). The essential difference between $\tilde{W}_{k}$ and $\tilde{W}_{\infty}$ is that $\tilde{W}_{k}$ gives increasing weight to lower quantiles in the income distribution of the most disadvantage group. Thus, in this respect $\tilde{\mathrm{W}}_{\mathrm{k}}$ captures also an aspect of inequality within types. 
Our justification for introducing the extended EOp welfare functions is twofold. First, besides parents' education (or other indicators one might have chosen), there might be other exogenous factors that affect individuals' achievements. Thus, given the definition of types based on father's education, differences in income within the most disadvantaged group might still be partly due to circumstances and partly be due to effort. The extended EOp welfare functions (2.8) accounts for the fact that part of the differences within the most disadvantaged group might still arise not from different levels of effort but rather from different circumstances. Second, the extended EOp welfare functions might be considered as a mixture of the pure EOp welfare function and the EO welfare functions. Thus, the extended EOp criterion provides a better basis for understanding differences in results produced by the pure EOp criterion and by the EO criteria. Note that the extended EOp welfare functions treat transfers from individuals that do not belong to the most disadvantage group to individuals that belong to the most disadvantage group as welfare improving. Moreover, transfers from richer to poorer individuals within the most disadvantage group is also welfare improving.

Note that $\min _{i} F_{i}^{-1}(t)$ defines the inverse of the following cumulative distribution function $(\tilde{F})$

$$
\tilde{F}(x)=\max _{i} F_{i}(x) .
$$

Thus, we may decompose the EOp welfare functions $\tilde{W}_{k}$ as we did for the EOp welfare functions $W_{k}$. Accordingly, we have that

$$
\tilde{W}_{k}=\tilde{W}_{\infty}\left(1-\tilde{C}_{k}\right), \quad k=1,2, \ldots
$$

where $\tilde{C}_{k}$, defined by

$$
\tilde{C}_{k}=1-\frac{\tilde{W}_{k}}{\tilde{W}_{\infty}}, \quad k=1,2, \ldots
$$

is a summary measure of inequality for the mixture distribution $\tilde{F}$.

Expression (2.10) demonstrates that the extended EOp welfare functions $\tilde{W}_{k}$ for $\mathrm{k}<\infty$ take into account value judgements about the trade-off between the mean income and the inequality in the distribution of income for the most (observed) EOp disadvantaged people. Thus, $\tilde{W}_{k}$ may be considered as an inequality within the most disadvantaged group adjusted version of the pure EOp welfare function that was introduced by Roemer (1998). Thus, $\tilde{W}_{k}$ for $k<\infty$ may be interpreted as an 
EOp welfare function that, in contrast to $\tilde{W}_{\infty}$, gives increasing weight to disadvantaged individuals who occupy low effort quantiles.

Note that the EOp criterion was originally interpreted as more acceptable from the point of view of individualistic societies. Our extended EOp welfare functions are concerned about inequality between observable types as well as inequality within the (observable) worst-off distribution defined by (2.9) and can in that sense be considered to capture features from both the pure EOp welfare function and the EO welfare functions. EOp looks at what happens to the distribution formed by the most disadvantaged segments of the intersecting observable type-specific distributions (defined by 2.9). Moreover, the pure version of the criterion only looks at the mean of the (observable) worst-off distribution. By contrast, EO takes into account the whole income distribution. For a given sum of incomes, EO will consider equality of income (everyone receives the same income) as the most desirable income distribution. The pure EOp will instead consider equality in mean incomes across observable types as the ultimate goal. Since the extended EOp combines these two criteria, transfers that increase the mean income of the worst-off group and/or reduce the income differentials between the individuals within the worst-off distribution are considered welfare improving by the extended EOp. Thus, in the case of a fixed total income also the extended EOp will consider equality of income as the most desirable distribution. However, by transferring money from the most advantaged type to the most disadvantaged type, EOp inequality may be reduced although transfers may be conflicting with the Pigou-Dalton transfer principle, which states that an income transfer from a richer to a poorer person reduces overall income inequality, provided that the receiver does not become richer than the donor. Note that the EOp and the EO criteria coincide if and only if the various type distributions coincide. Moreover, we want to stress that while the pure EOp is a special case of our generalized EOp, the latter is not a special case of EO. The two criteria (EO and EOp) are not nested. Accordingly, theoretical considerations cannot be used to clarify whether EOp or EO will favors the most inequality averse tax structure. This is simply an empirical question. Thus, whether it is more "efficient" to reduce inequality between types or within the worst-off distribution depends on the specific situation. When labour supply responses to taxation are taken into account the composition of observable types in the worst-off distribution will change and depend on the chosen welfare function as well as on the considered tax rule. Thus, the large heterogeneity in labour supply responses to tax changes that is captured by our model(s) makes it impossible to state anything on EOp- or EO-optimality before the simulation exercises have been completed. 


\section{Optimal tax-transfer rules}

In what follows we determine - by microeconometric simulation - the income tax-transfer rules that solve problem (2.6) defined in the previous section. It is important to stress that the tax-transfer rules we consider are assumed to depend only on income (as much as current rules essentially do). In particular, they do not depend on the "type" (father's education in this exercise) the individuals belong to. In other words, we aim at finding the tax-transfer rules that best conform to the EOp criterion within the class of rules that only depend on income. Despite the fact that "types" might be observable, we postulate that it is not practical or realistic or politically acceptable to actually use them as an argument of the tax-transfer rule. We take therefore a second-best perspective where only income can be used as an instrument.

The optimal rules are determined computationally, i.e. we employ a microeconometric model that is capable of simulating choices (labour supply) of couples and singles facing alternative tax-transfer rules. Given a parametric representation of the tax-transfer rule, we iteratively search the parameter space until the social welfare function is maximized under the constraint of a constant total net tax revenue. The model is explained in detail in the Appendix. The sample used for the estimation and the simulation of the model is obtained from the Bank-of-Italy 1993 Survey of Household Income and Wealth (SHIW 1993). It contains single females, single males, and couples that are between 19 and 54 year old. To capture the heterogeneity in preferences we have estimated three separate models of labour supply: one for single females, one for single males and one for couples. The main features of the 1993 tax rule - i.e. the actual tax rules the households face - are briefly illustrated in the Appendix.

The tax reform simulations consist of five main steps:

1. The tax rule is applied to individual earners' gross incomes in order to obtain disposable incomes. New labour supply responses in view of a new tax rule are taken into account by the household labour supply models for singles and couples described in the Appendix. Note that the utility functions (and choice sets) of the underlying micro-econometric model(s) are stochastic. Thus, we use stochastic simulation to find, for each individual/couple, the optimal choice given a taxtransfer rule. The simulations are made under the conditions of unchanging total tax revenue and non-negative disposable household incomes.

2. To each decision making individual between 18 and 54 years old, an equivalent income is imputed, computed as total disposable household income divided by the square root of the number of household members.

3. We then build the individual equivalent income distributions $F_{1}, F_{2}$ and $F_{3}$ for the types defined according to parental (actually father's) education: less than 5 years (type 1), 5-8 years (type 2) and more than 8 years (type 3 ). 
4. Finally, we compute $\tilde{W}_{k}$ for $k=1,2,3$ and $\infty$.

5. Optimization is performed by iterating the above steps, in order to find the tax rule that produces the highest value of $\tilde{W}_{k}$ for each value of $\mathrm{k}$ under the constraint of unchanged tax revenue, provided that the tax rule is a member of certain sets of two- and three-parameter tax rules.

\subsection{EOp-evaluation of alternative two-parameter tax rules}

The alternative two-parameter tax rules are of the following type:

$x=c+(1-t) y$,

where

$\mathrm{y}=$ gross income,

$\mathrm{x}=$ disposable income,

$\mathrm{c}=$ lump-sum transfer (positive or negative), and

$\mathrm{t}=$ constant marginal tax rate.

This class of tax-transfer rule is the same as that considered in Roemer et al. (2003). Here however we use a more sophisticated empirical strategy. In Sections 3.2 and 5 we will consider 3-parameter taxtransfer rules.

Note that the income and tax figures below are measured in 1000 ITL since the model is estimated for a pre-EURO year (to get the EURO equivalent just divide the figures by 1.93627). The results of the two-parameter tax reform simulations are summarised in Tables 1 and 2 and in Figure 1.

Table 1. Optimal two-parameter tax systems under various EOp social objective criteria $\left(\tilde{\mathbf{W}}_{k}\right)$

\begin{tabular}{ccccc}
\hline $\mathrm{k}$ & 1 & 2 & 3 & $\infty$ \\
\hline marginal tax rate, $\mathrm{t}$ & .774 & .637 & 0 & 0 \\
$\begin{array}{c}\text { lump-sum } \\
\text { tax/transfer, c }\end{array}$ & 11,500 & 9,500 & $-5,790$ & $-5,790$ \\
\hline
\end{tabular}

Table 1 presents the EOp-optimal affine tax rules for different values of k, i.e. for different degrees of concern for within type inequality. Recall that the higher is $\mathrm{k}$, the lower is the concern for within type inequality.

As demonstrated by Table 1 the optimal policy is very sensitive to the value of $\mathrm{k}$. For $k \geq 3$, the EOp-optimal tax rule is the pure lump-sum tax (i.e. $t=0$ and $c<0$ ) whereas for $k \leq 2$ the optimal tax rule consists of a very high marginal tax rate and a positive lump-sum transfer. An implication is 
that the concern for the equality of opportunity by itself does not imply high marginal tax rates. Only if we also account for within type inequality, does the optimal policy entail high marginal tax rates.

In order to interpret correctly our results, it should be remembered that the lump-sum rule considered here is not the lump-sum rule envisaged in the $2^{\text {nd }}$ Welfare Theorem, which would require individual (or household) - specific lump-sum taxes or transfers. In our exercise, the lump-sum rule envisages taxes or transfers equal for everyone.

Figure 1. Distributions of observed equivalent income by type. 1000 ITL

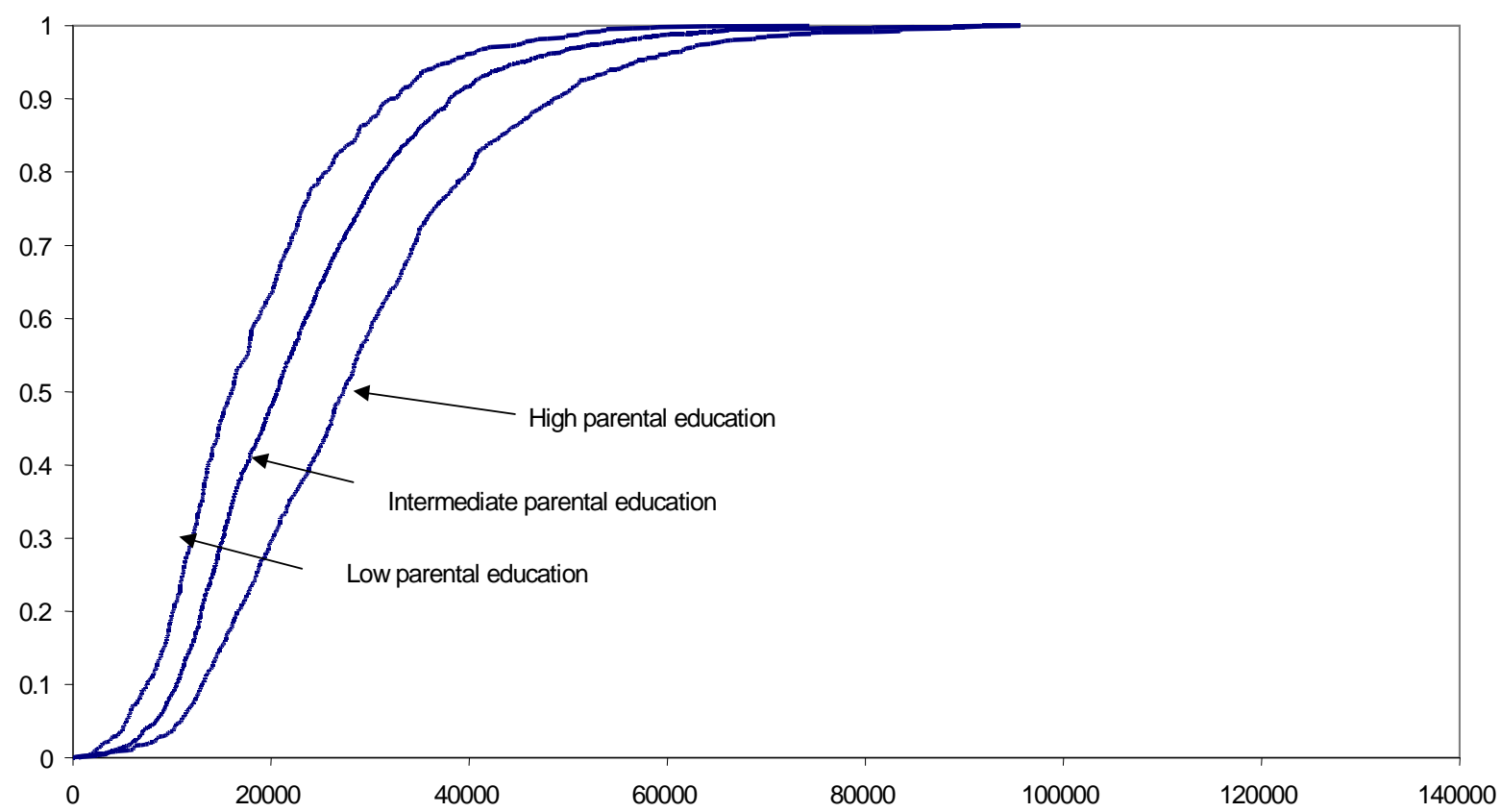

Figure 2. Distributions of individual equivalent income by type under the EOp2(1) and EOp2(3) tax systems. 1000 ITL

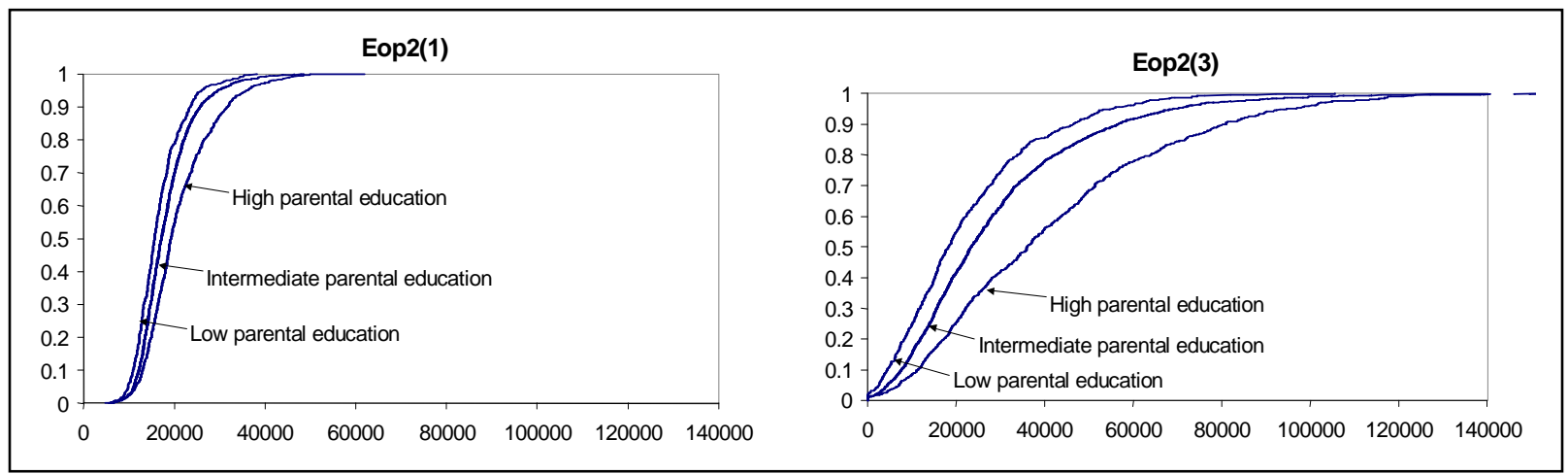

Table 2 and Figures 1 and 2 give more details. The graphs illustrate the equivalent income distributions under the actual 1993 tax rule (Figure 1) and under the EOp-optimal rules for $k=1$ and $k \geq 3$ (Figure 2). Table 2 reports the value of the EOp criterion for different tax rules. In particular, we 
focus on the comparison between the observed rule (1993), the pure flat tax (a theoretical benchmark), and the three linear rules that are EOp optimal under different values of $k$. In each column (i.e. for each $\mathrm{k}$ ) the bold figure is the maximised value of the EOp criterion, i.e. it corresponds to the EOpoptimal tax rule. EOp2(r) denotes the EOp-optimal affine tax rule when $k=r$.

Table 2. EOp-performance $\left(\tilde{W}_{k}\right)$ of the 1993 tax system, a flat tax system and three different EOp-optimal two-parameter tax systems

\begin{tabular}{|c|c|c|c|c|c|}
\hline \multirow[b]{2}{*}{ Tax system } & \multirow{2}{*}{$\begin{array}{r}\text { Social objective } \\
\text { function } \\
\left(\tilde{\mathrm{W}}_{\mathrm{k}}\right)\end{array}$} & \multicolumn{4}{|c|}{$\mathrm{k}$} \\
\hline & & 1 & 2 & 3 & $\infty$ \\
\hline 1993 tax system & & 10,523 & 12,797 & 13,893 & 18,323 \\
\hline Flat tax & $\left(\begin{array}{c}\mathrm{t}=.181 \\
\mathrm{c}=0\end{array}\right)$ & 10,834 & 13,496 & 14,823 & 20,449 \\
\hline EOp2 (1) & $\left(\begin{array}{c}t=.774 \\
c=11,500\end{array}\right)$ & 12,661 & 13,652 & 14,077 & 15,641 \\
\hline EOp2 (2) & $\left(\begin{array}{c}\mathrm{t}=.637 \\
\mathrm{c}=9,500\end{array}\right)$ & 12,406 & 13,660 & 14,237 & 16,486 \\
\hline EOp2 (3) & $\left(\begin{array}{c}t=0 \\
c=-5,790\end{array}\right)$ & 9,942 & 13,270 & 14,992 & 22,231 \\
\hline
\end{tabular}

Table 2 enables us to compare the EOp performance of the various rules for a given $\mathrm{k}$ (note that the comparison only makes sense between elements of the same column). We can see that although the flat tax is never EOp-optimal, for any value of $k$, it improves upon the observed 1993 rule. More generally, one can always find an affine tax rule that is EOp-preferred to the observed 1993 one. However, the direction along which one can find EOp-optimal tax rules depends crucially on the value of $k$. If $k=1$ one has to move towards very high marginal tax rates (coupled with high transfers). If $k$ is greater than 1, then the EOp-optimal tax rules require lower marginal tax rates - and more revenue collected through the lump-sum part of the tax. These aspects are further illustrated by Figure 3, where we draw the curve - in the (c, t) plane - of the revenue-constant affine tax rules, and for any $k$ we indicate the sets of tax rules with a lower or with a higher EOp performance with respect to the observed rule. As $k$ increases the graphs in Figure 3 demonstrate that the more we reduce the marginal tax rate - and the more revenue we collect through lump-sum taxation - the better is the EOpperformance.

The fact that the optimal tax rule is the pure lump-sum tax, provided that we do not put too much weight on within type inequality, is a somewhat striking result in itself. After all, EOp is an 
egalitarian criterion, and one would expect it to favour higher marginal tax rates. How can we explain this apparently counter-intuitive result? A possible explanation lies with the relatively high labour supply response of the least advantaged individuals. Since the EOp-criterion requires the maximisation of a weighted average of the incomes of the least advantaged type, and since the labour supply of these individuals turns out to be very responsive to higher net wage rates, it follows that lower marginal tax rates (or, in the limit, a marginal tax rate equal to 0 ) can in fact improve substantially the welfare of this group. However, this effect may be counterbalanced if we give enough weight (low value of $k$ ) to low effort individuals. Table 4 gives some support to this argument by illustrating the labour supply response of the different types when facing alternative tax rules. When the pure lump-sum tax is applied, the labour supply (and therefore the available income) of type 1 (the most disadvantaged group) increases much more (as percentage variation) than labour supply of types 2 or $3 .^{8}$

The different population considered and the heterogeneity of the labour supply elasticity most likely also play a crucial role in explaining the differences between our results and those obtained by Roemer et al. (2003), where only males are considered and a fixed value of the labour supply elasticity is set equal to 0.06 . The social welfare criterion corresponding to the one adopted in Roemer et al. (2003) is $\tilde{W}_{\infty}$. For this social welfare function, we get that the optimal rule is a pure lump-sum $\operatorname{tax}=5790$ (tax rate $=0)$. Roemer et al. (2003) obtain instead an optimal tax rate that varies from .65 to .83 and an optimal (positive) lump-sum transfer that varies from 16630 to 21300 . In order to get optimal rules that are close to those of Roemer et al. (2003) we should use $\tilde{W}_{1}$, i.e. the social welfare function corresponding to the Bonferroni version of the generalized version of the EOp crierion.

Overall it seems that the heterogeneity of labour supply behaviour plays a crucial role in shaping the optimal tax rules for a given social welfare function: this gives support to the use of microeconometric simulation tools for investigating optimal taxation issues.

\footnotetext{
${ }^{8}$ To be sure, a bias in favour of the lump-sum tax might be due to the fact that we equate income and welfare. When accounting for the value of leisure (object of on-going research), the policy prescriptions might change.
} 
Table 3. Decomposition of EOp social welfare $\left(\tilde{W}_{k}\right)$ under the 1993 tax system, a flat tax system and various EOp-optimal two-parameter tax systems

\begin{tabular}{l|cccc}
\hline \multirow{2}{*}{ Tax system } & $\tilde{\mathrm{W}}_{\infty}$ & \multicolumn{3}{c}{ Measure of inequality } \\
\cline { 2 - 5 } 1993 tax system & & $\tilde{\mathrm{C}}_{1}$ & $\tilde{\mathrm{C}}_{2}$ & $\tilde{\mathrm{C}}_{3}$ \\
Flat tax $\left(\begin{array}{c}\mathrm{t}=.181 \\
\mathrm{c}=0\end{array}\right)$ & 18,323 & .426 & .302 & .242 \\
EOp2 (1) $\left(\begin{array}{c}\mathrm{t}=.774 \\
\mathrm{c}=11,500\end{array}\right)$ & 20,449 & .470 & .340 & .275 \\
EOp2 (2) $\left(\begin{array}{c}\mathrm{t}=.637 \\
\mathrm{c}=9,500\end{array}\right)$ & 15,642 & .191 & .127 & .100 \\
EOp2 (3) $\left(\begin{array}{c}\mathrm{t}=0 \\
\mathrm{c}=-5,790\end{array}\right)$ & 16,486 & & .171 & .136 \\
\hline
\end{tabular}

Figure 3. Sets of revenue constant affine tax systems under different EOp welfare criteria $\left(\tilde{W}_{k}\right)$

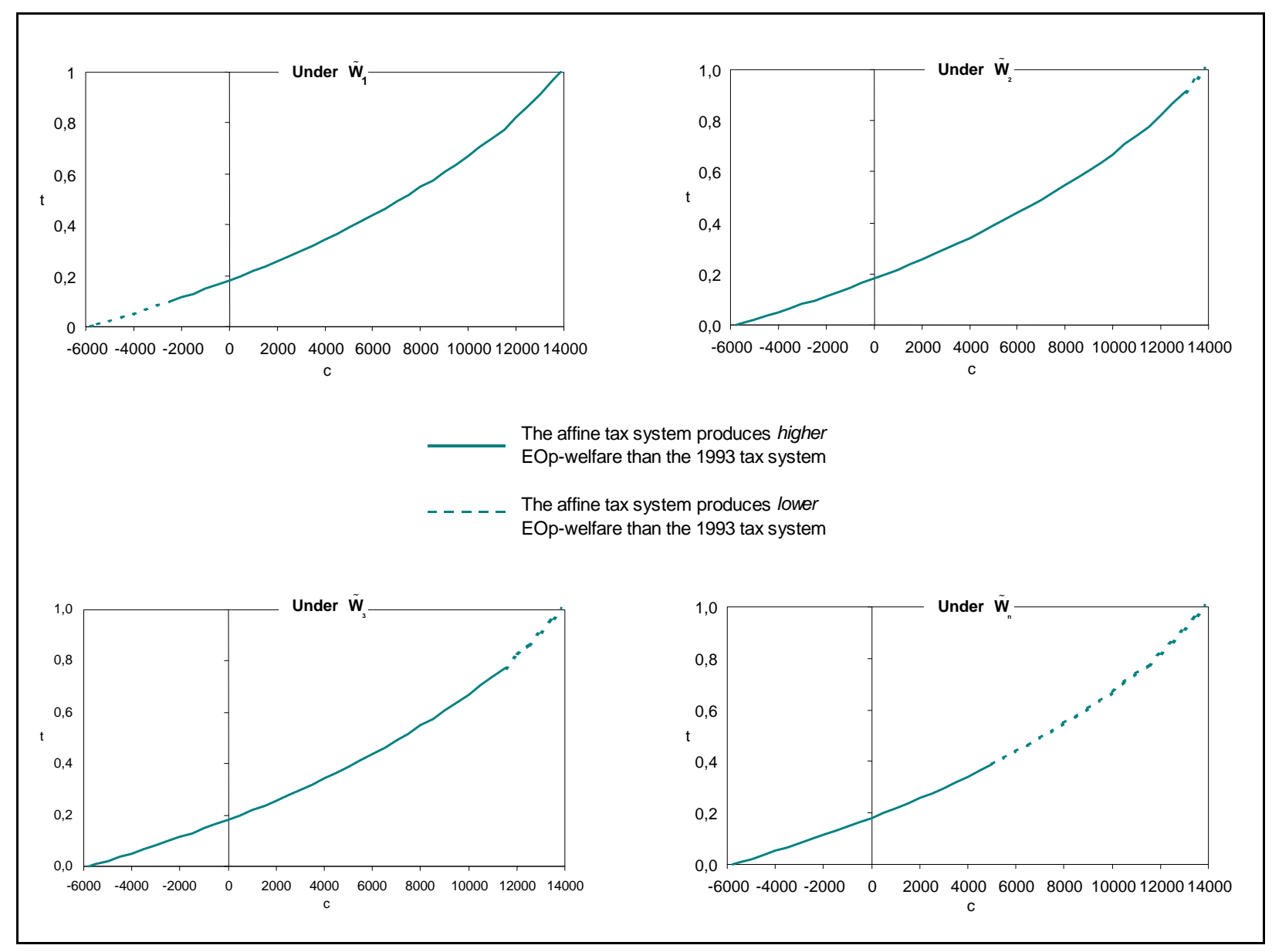


Table 4. Labour supply by types under different tax systems*

\begin{tabular}{l|cccc}
\hline Tax system & All & \multicolumn{3}{c}{ Type } \\
\cline { 2 - 5 } & 1383 & 1279 & 1383 & 1469 \\
Flat tax $\left(\begin{array}{c}\mathrm{t}=.181 \\
\mathrm{c}=0\end{array}\right)$ & $1391(+0.58)$ & $1369(+7.04)$ & $1362(+1.52)$ & $1471(+0.14)$ \\
EOp2 (1) $\left(\begin{array}{c}\mathrm{t}=.774 \\
\mathrm{c}=11,500\end{array}\right)$ & $1095(-20.82)$ & $1109(-13.29)$ & $1087(-21.40)$ & $1100(-25.12)$ \\
EOp2 (2) $\left(\begin{array}{c}\mathrm{t}=.637 \\
\mathrm{c}=9,500\end{array}\right)$ & $1160(-16.12)$ & $1142(-10.71)$ & $1148(-16.99)$ & $1200(-18.31)$ \\
EOp2 (3) $\left(\begin{array}{c}\mathrm{t}=0 \\
\mathrm{c}=-5,790\end{array}\right)$ & $1487(+7.52)$ & $1450(+13.37)$ & $1459(+5.50)$ & $1578(+7.42)$ \\
\hline
\end{tabular}

*Percentage changes relative to the labour supply under the 1993 tax system in parentheses.

What happens to specific groups of people under the EOp-optimal rules and in particular under the pure lump-sum policy? Table 5 presents, for various sub-samples, their composition in terms of EOptypes, the average net observed income in 1993, and the change in average income when the lumpsum rule is applied. The results in Table 5 give a more vivid understanding of the effects of the "reform" from the viewpoints of efficiency and equality. All the sub-samples on average gain in the sense that they get more income. If we look at the gains across types, we see that types 2 or 3 almost always gain proportionately more than type 1 . However this is not relevant from the point of view of the EOp criterion, according to which we only care about what happens to the worst-off type for each quantile (in our case, in practice, this is type 1). Under the lump-sum rule, type 1 gains more than under the alternative rules; it does not matter if type 2 and 3 gain even more. Where do these gains come from? Clearly there are two (interdependent) channels, higher net wages (in fact an agent gets the whole gross wage under the lump-sum rule) and higher labour supply. The labour supply response is documented in Table 4. For example, we can compute from Table 5 that overall average income increases by 54 per cent gross of the lump-sum tax of 5,790,000 ITL. Since the overall increase in labour supply amounts to 7.5 per cent (from Table 4), we have a 46.5 per cent gain attributable to the increase in net wage and to the interaction between wage and labour supply across the sample. We have seen that the lump-sum rule is outcome disequalizing (Table 3). However we know that the generalised EOp index is only affected by the inequality among the individuals belonging to the worstoff type. If we look at what is going on more generally in the whole sample, the effect upon distribution is less clear-cut. For example, the relative gain of the poor is larger than the relative gain of the non-poor. 
Table 5. Relative proportions, mean observed individual (disposable equivalent) income $\left(W_{\text {obs }}\right)$ and changes in mean individual income $\left(\mathrm{W}_{\infty}-\mathrm{W}_{\text {obs }}\right)$ by gender, family status, economic status (poverty) and family background (type) when the tax regime is changed to lump-sum taxation. In 1000 LIT

\begin{tabular}{|c|c|c|c|c|c|}
\hline \multirow{2}{*}{$\begin{array}{l}\text { Individual and } \\
\text { household } \\
\text { characteristics }\end{array}$} & & \multicolumn{4}{|c|}{ Household type (by family background) } \\
\hline & & 1 & 2 & 3 & All \\
\hline \multirow{3}{*}{ All } & Proportion (per cent) & 20.3 & 54.7 & 25.0 & 100 \\
\hline & Mean income & 21,107 & 22,831 & 29,312 & 23,540 \\
\hline & $\begin{array}{l}\text { Changes in mean } \\
\text { income }\end{array}$ & 3,907 & 5,794 & 12,011 & 6,969 \\
\hline \multirow{3}{*}{ Single males } & Proportion (per cent) & 19.9 & 51.7 & 28.4 & 100 \\
\hline & Mean income & 22,369 & 28,480 & 34,046 & 28,843 \\
\hline & $\begin{array}{l}\text { Changes in mean } \\
\text { income }\end{array}$ & 3,210 & 7,013 & 7,343 & 6,350 \\
\hline \multirow{3}{*}{ Single females } & Proportion (per cent) & 15.8 & 51.7 & 32.6 & 100 \\
\hline & Mean income & 18,076 & 20,110 & 26,085 & 21,734 \\
\hline & $\begin{array}{l}\text { Changes in mean } \\
\text { income }\end{array}$ & 3,134 & 2,568 & 4,412 & 3,258 \\
\hline \multirow{3}{*}{ Two person households } & Proportion (per cent) & 15.3 & 51.2 & 33.5 & 100 \\
\hline & Mean income & 24,377 & 28,613 & 33,913 & 29,741 \\
\hline & $\begin{array}{l}\text { Changes in mean } \\
\text { income }\end{array}$ & 7,153 & 9,781 & 14,909 & 11,097 \\
\hline \multirow{3}{*}{$\begin{array}{l}\text { Three person } \\
\text { households }\end{array}$} & Proportion (per cent) & 16.5 & 55.0 & 28.5 & 100 \\
\hline & Mean income & 20,091 & 24,795 & 29,050 & 25,235 \\
\hline & $\begin{array}{l}\text { Changes in mean } \\
\text { income }\end{array}$ & 4,678 & 5,066 & 14,333 & 7,648 \\
\hline \multirow{3}{*}{$\begin{array}{l}\text { Households with more } \\
\text { than three persons }\end{array}$} & Proportion (per cent) & 23.5 & 55.8 & 20.7 & 100 \\
\hline & Mean income & 16,848 & 20,516 & 27,349 & 21,064 \\
\hline & $\begin{array}{l}\text { Changes in mean } \\
\text { income }\end{array}$ & 3,022 & 5,153 & 9,785 & 5,608 \\
\hline \multirow{3}{*}{ Poor individuals } & Proportion (per cent) & 39.2 & 50.4 & 10.4 & 100 \\
\hline & Mean income & 7,235 & 7,720 & 7,424 & 7,500 \\
\hline & $\begin{array}{l}\text { Changes in mean } \\
\text { income }\end{array}$ & 5,276 & 7,487 & 13,174 & 7,216 \\
\hline \multirow{3}{*}{ Non-poor individuals } & Proportion (per cent) & 18.0 & 55.2 & 26.8 & 100 \\
\hline & Mean income & 21,320 & 24,541 & 30,368 & 25,528 \\
\hline & $\begin{array}{l}\text { Changes in mean } \\
\text { income }\end{array}$ & 3,537 & 5,603 & 11,955 & 6,939 \\
\hline
\end{tabular}




\subsection{EOp-evaluation of alternative three-parameter tax rules}

One might suspect that the results - in particular the EOp-optimality of a pure lump-sum tax for $\mathrm{k}=3$ or greater - are somewhat forced by the fact that we restrict the simulation to a two-dimensional class of tax rules. Since the disadvantaged individuals are more responsive - in terms of labour supply than the rich and/or advantaged individuals, we should be able to improve upon the pure lump-sum tax or upon the high marginal rate rules, by adopting a two-dimensional tax rule. Here we explore this policy direction. The class of tax rules considered is defined as follows:

$$
x=\left\{\begin{array}{l}
c+\left(1-t_{1}\right) y \text { if } y \leq \bar{y} \\
c+\left(1-t_{1}\right) \bar{y}+\left(1-t_{2}\right)(y-\bar{y}) \text { if } y>\bar{y}
\end{array}\right.
$$

where

$x=$ disposable income

$y=$ gross income,

$\bar{y}=$ average individual gross income in Italy on the survey year (1993).

Clearly one could consider more general and flexible rules. ${ }^{9}$ Here, however, our aim is not the design of a realistic optimal system but rather the use of a stylized and easy-to-visualize class of tax-transfer rules as a basis for comparing the implications of different evaluation criteria. On the other hand, even a rule with two brackets is not devoid of realism since the recent trend for tax reform move in the direction of simplifying the rules and reducing the number of brackets.

Table 6 reports the optimal three-parameter rules for different values of $k$. For example, for $\mathrm{k}=1$ the optimal rule is defined by a transfer $\mathrm{c}=12,500$, a first marginal tax rate $t_{1}=0.856$ and a second marginal tax rate $t_{2}=0.776$. By comparing Table 6 with Table 1 , we see that the EOp-optimal rules differ significantly depending on whether one considers a two-parameter (Table 1) or a threeparameter rule (Table 6). When $\mathrm{k}=1$, the three-parameter EOp-optimal rule gives two very high and slightly regressive tax rates ${ }^{10}$ complemented by a large positive transfer, inducing a net-vs-gross income profile close to the ones implied by the Negative Income Tax schemes. The most marked differences with respect to the two-parameter case are found when using the $\mathrm{k}=2$. While the twoparameter case called for tax rate over 60 per cent combined with a positive transfer of 9,500,000 ITL, the three-parameter case entails two very different tax rates with a marked progressive structure (from 25 per cent to 53 per cent) and a much lower transfer $(3,500,000$ ITL). For any $k \geq 3$, the two-

\footnotetext{
${ }^{9}$ See for example Aaberge and Colombino (2008).

${ }^{10}$ Regressive in the sense that the marginal tax rate decreases with income.
} 
parameter case chooses the pure lump-sum tax as the EOp-optimal policy. When we use a threeparameter rule, with $\mathrm{k}=3$, we still have a positive tax rate (17 per cent) for the higher incomes, combined with a 3,500,000 ITL lump-sum tax. However, when we employ the pure EOp-welfare function $(\mathrm{k}=\infty)$, we are back to the EOp-optimality of the pure lump-sum tax.

It is worth mentioning that when the EOp-version of the Gini welfare function is adopted, the optimal tax rule is close to the actual one if not for the important difference of prescribing a universal lump-sum positive transfer of 3,500,000 ITL, which has no comparable counterpart in the actual system.

Table 7 is the analogue of Table 3 for the three-parameter rule. It shows the decomposition of the EOp social welfare function for different values of $\mathrm{k}$ and different tax rules, that is, the current 1993 rule and the four EOp-optimal rules of Table 6, with EOp3(r) denoting the EOp-optimal threeparameter tax rule when $\mathrm{k}=\mathrm{r}$.

Table 7 also provides an illustration of the equity-efficiency trade-off. The lump-sum rule (i.e. EOp $3(\infty)$ ) is the most efficient one (measuring efficiency with $\tilde{\mathrm{W}}_{\infty}$ ). If we adopt an egalitarian criterion, e.g. the Gini version of the EOp criterion, the optimal rule is EOp3(2). We have a loss of efficiency equal to $22,231-18,508$. However the loss of efficiency is more than compensated by a gain in equality: indeed, the Gini coefficient decreases from .403 to .253 and the Gini EOp welfare function increases from $22,231(1-0.403)=13,271$ to $18,508(1-0.253)=13,825$.

Table 6. Optimal three-parameter tax systems under various EOp social objective criteria $\left(\tilde{W}_{k}\right)$

\begin{tabular}{ccccc}
\hline $\mathrm{k}$ & 1 & 2 & 3 & $\infty$ \\
\hline $\mathrm{t}_{1}$ & .856 & .251 & 0 & 0 \\
$\mathrm{t}_{2}$ & .776 & .531 & .168 & 0 \\
\hline $\mathrm{c}$ & 12,500 & 3,500 & $-3,500$ & $-5,790$ \\
\hline
\end{tabular}


Table 7. Decomposition of EOp social welfare $\left(\tilde{W}_{k}\right)$ under various three-parameter tax systems

\begin{tabular}{l|cccc}
\hline \multirow{2}{*}{ Tax system } & $\tilde{\mathrm{W}}_{\infty}$ & \multicolumn{3}{c}{ Measure of inequality } \\
\cline { 2 - 5 } 1993 tax system & & $\tilde{\mathrm{C}}_{1}$ & $\tilde{\mathrm{C}}_{2}$ & $\tilde{\mathrm{C}}_{3}$ \\
\hline EOp3 (1) $\left(\begin{array}{c}\mathrm{t}_{1}=.856 \\
\mathrm{t}_{2}=.776 \\
\mathrm{c}=12,500\end{array}\right)$ & 18,323 & .426 & .302 & .242 \\
EOp3 (2) $\left(\begin{array}{c}\mathrm{t}_{1}=.251 \\
\mathrm{t}_{2}=.531 \\
\mathrm{c}=3,500\end{array}\right)$ & 15,393 & .176 & .116 & .091 \\
EOp3 (3) $\left(\begin{array}{c}\mathrm{t}_{1}=0 \\
\mathrm{t}_{2}=.168 \\
\mathrm{c}=-3,500\end{array}\right)$ & 18,508 & & .253 & .201 \\
EOp3 $(\infty)\left(\begin{array}{c}\mathrm{t}_{1}=\mathrm{t}_{2}=0 \\
\mathrm{c}=-5,790\end{array}\right)$ & & & .364 & .285 \\
\hline
\end{tabular}

\section{Comparison of empirical results based on EOp and EO criteria}

In this section we focus upon the evaluation of the EOp-optimal policies (illustrated in Section 3) using the more traditional evaluation criterion of equality of outcome (EO criterion, see Section 2). Table 8 reports the EO-performance, that is, the level of the EO social welfare function (defined in Section 2) of five policies discussed above for various values of $\mathrm{k}$. The policies are the observed 1993 tax rule, and the four EOp-optimal three-parameter rules for $k=1,2,3$ and $\infty$. The Table shows the decomposition of the EO-criterion into the efficiency and the inequality terms. More generally, we have also searched for the EO-optimal rule within the whole classes of the two-parameter and threeparameter tax rules, and it always turns out that a universal lump-sum tax is optimal whatever the value of $\mathrm{k}$. Thus, if we do not explicitly account for inequality between types according to the EOp criterion, the optimal policy always consists in a zero marginal tax rate coupled with a positive universal lump-sum tax, whatever the degree of inequality aversion. Table 8 clarifies that this result is due to very large efficiency effects of the lump-tax rule, large enough to over-compensate the also large inequality effects.

It might appear paradoxical that, overall, EOp requires more redistribution (through marginal tax rates) than EO. However the paradox is only apparent. EOp is motivated by a methodological position that focuses on inequality due to circumstances: but this position does not necessarily imply less redistribution - a consequence of EO and EOp being non-nested criteria. 
Table 8 can also be read from the perspective of the efficiency-equity trade-off, as we did when commenting Table 7 at the end of Section 3.2 - but this time adopting the EO criterion. The EOmost efficient policy is a lump-sum tax $=5,790$ (i.e. EOp3 $(\infty)$ ). This policy entails a mean income $=$ 30,510. However it also implies a high level of inequality, measured for example by the Gini coefficient $\left(\mathrm{C}_{2}\right)=.402$. Let us consider a more egalitarian policy, such as EOp3(2). This policy reduces the $\mathrm{C}_{2}$ to .255 , however it also brings about a loss of efficiency equal to $10,033=30,510$ 21,477 .

Table 8. Decomposition of the EO social welfare $\left(W_{k}\right)$ with respect to mean and income inequality under different tax systems

\begin{tabular}{l|cccc}
\hline Tax system & Mean income & \multicolumn{3}{c}{ Measure of inequality } \\
\cline { 2 - 5 } 1993 tax system & & $\mathrm{C}_{1}$ & $\mathrm{C}_{2}$ & $\mathrm{C}_{3}$ \\
\hline EOp3 (1) $\left(\begin{array}{c}\mathrm{t}_{1}=.856 \\
\mathrm{t}_{2}=.776 \\
\mathrm{c}=12,500\end{array}\right)$ & 23,540 & .416 & .295 & .237 \\
EOp3 (2) $\left(\begin{array}{c}\mathrm{t}_{1}=.251 \\
\mathrm{t}_{2}=.531 \\
\mathrm{c}=3,500\end{array}\right)$ & 16,560 & .193 & .130 & .104 \\
EOp3 (3) $\left(\begin{array}{c}\mathrm{t}_{1}=0 \\
\mathrm{t}_{2}=.168 \\
\mathrm{c}=-3,500\end{array}\right)$ & 21,477 & .364 & .255 & .203 \\
EOp3 $(\infty)\left(\begin{array}{c}\mathrm{t}_{1}=\mathrm{t}_{2}=0 \\
\mathrm{c}=-5,790\end{array}\right)$ & 27,573 & & .363 & .294 \\
\hline
\end{tabular}

\section{Optimal rules when a universal lump-sum tax is not feasible}

As we have seen in previous sections, in many cases it turns out that the socially optimal tax rule is a universal lump-sum tax. Notice that this lump-sum tax is identical for everyone and is not to be confused with the policy of individualized lump-sum taxes that would be optimal in a first-best world. However, even a universal lump-sum tax might be not feasible, for example because it might be judged as not politically acceptable.. Therefore we also computed optimal tax rules where lump-sum positive transfers are allowed but not lump-sum taxes. The results are summarised in Tables 9 and 10 respectively for the EOp and the EO criterion. As it is the case with the policies computed in the 
previous sections, the optimal no-lump-sum policies are the same under EOp and under EO when $k=$ $\infty$, with no transfers, a $31.3 \%$ marginal tax rate on the first segment and a $0 \%$ marginal tax rate on the second segment. This same rule remains the best one under EO for $k=3$ and $k=2$. For the same values of $k$, the EOp criterion prescribes instead a progressive rules (for $k=2$, it also requires a positive transfer). For $k=1$ the two criteria diverge again: EOp prescribes a very large transfer together with very high (slightly regressive) marginal rates, while EO prescribes a modest transfer and much lower (regressive) marginal rates. Overall, as was also the case with the policies admitting lumpsum taxes, the EOp criterion seems to require more redistribution than the EO criterion.

Table 9. Optimal three-parameter tax systems under various EOp social objective criteria $\left(\tilde{W}_{\mathbf{k}}\right)$. Lump-sum taxes not feasible

\begin{tabular}{ccccc}
\hline $\mathrm{k}$ & 1 & 2 & 3 & $\infty$ \\
\hline $\mathrm{t}_{1}$ & .856 & .251 & 0.106 & .313 \\
$\mathrm{t}_{2}$ & .776 & .531 & 0.346 & 0 \\
\hline $\mathrm{c}$ & 12,500 & 3,500 & 0 & 0 \\
\hline
\end{tabular}

Table 10. Optimal three-parameter tax systems under various EO social objective criteria $\left(\tilde{\mathbf{W}}_{k}\right)$. Lump-sum taxes not feasible

\begin{tabular}{ccccc}
\hline $\mathrm{k}$ & 1 & 2 & 3 & $\infty$ \\
\hline $\mathrm{t}_{1}$ & .298 & .313 & .313 & .313 \\
$\mathrm{t}_{2}$ & .178 & 0 & 0 & 0 \\
\hline $\mathrm{c}$ & 2000 & 0 & 0 & 0 \\
\hline
\end{tabular}

\section{Conclusion}

We have used a micro-econometric model of household labour supply in Italy in order to simulate and identify optimal (second-best) income tax-transfer rules within classes of two- and three-parameter rules according to the criterion of Equality of Opportunity as developed by Roemer (1998). We have also offered an extended version of the EOp criterion that permits us to complement the pure EOp criterion with a variable degree of aversion to inequality within the worst-off distribution. When we admit the feasibility of universal (i.e. not individual-specific) lump-sum taxes, the optimal tax rule turns out to be in fact a universal lump-sum tax, under the pure EOp criterion or under the extended EOp with moderate degrees of aversion to inequality $(k=3)$ within the worst-off distribution. The result seems to depend on a relatively high labour supply response from the most disadvantaged type: 
the labour supply incentives - and the efficiency effects for the most disadvantaged - generated by the pure lump-sum tax are large enough to overcome the disequalizing effects of lump-sum taxation. A high degree of inequality aversion ( $k$ less than 3 ) instead produces EOp-optimal rules with strictly positive marginal tax rates. It is worth mentioning that when the EOp-version of the Gini welfare function is adopted, the optimal tax rule is close to the actual one if not for the important difference of prescribing a universal lump-sum positive transfer of 3,500,000 ITL (= 1807 Euros), which has no comparable counterpart in the actual system.

On the other hand, when using the equality of outcome (EO) criterion, the universal lumpsum tax always turns out to be optimal, at least with respect to the classes of two- and three-parameter rules. Overall, the results do not conform to the perhaps common expectation that the EO criterion is more supportive of "interventionist" (redistributive) policies than an EOp approach. On the contrary, our data and our model indicate that EO never calls for redistribution, and only if an extended EOp criterion is introduced may redistributive intervention (through increasing marginal tax rates and/or positive transfers) be optimal depending on the degree of social aversion to inequality. ${ }^{11}$

We also identified the optimal rules when assuming that only universal lump-sum positive transfers (not taxes) are feasible. In this case the pure EOp-criterion and utilitarian EO-criterion dictate the same rule, namely a regressive system where all the taxes are collected form incomes in the first bracket. This same rule remains the optimal one under the EO-criterion except in the Bonferroni case $(k=1)$. The optimal rules become definitely more redistributive when adopting the extended EOpcriterion. In particular, in the Gini case $(\mathrm{k}=2)$ the optimal rule is close enough to the actual one, with the important difference that the optimal rule envisages a lump-sum transfer of approximately 1807 Euros.

Looking at the results from a methodological perspective, the importance of heterogeneous labour supply responses in shaping the optimal tax rules suggest that simulation based on micorconometric models is a useful tool for investigating optimal taxation issues.

\footnotetext{
${ }^{11}$ The policy prescription might change if we included the value of leisure in the measurement of individual welfare. For example, since under the pure lump-sum tax people work (and earn) a lot more, it might be the case that, when account is taken of their reduced leisure, the lump-sum tax is not so desirable. Including the value of leisure will be pursued in future work.
} 


\section{Appendix}

\section{A.1. The microeconometric model}

The modelling approach of this paper differs from the traditional textbook labour supply model since we treat the utility function as a random variable and model labour supply decision as a random utility maximization problem. This framework can be considered as an extension of the standard multinomial logit model (see Dagsvik (1994) and Aaberge et al. (1999) for further details). For the sake of completeness we give a brief outline of this modelling framework. The agents choose among jobs, each job being defined by a wage rate $w$, hours of work $h$ and other characteristics $j$. For expository simplicity we consider in what follows a single person household, although the model we estimate considers both singles and couples. The problem solved by the agent looks like the following:

$$
\max _{(x, h, j) \in B} U(x, h, j)
$$

under the budget constraint $x=f(w h, m)$, where

$h=$ hours of work

$w=$ gross wage rate

$j=$ other job and/or household characteristics

$m=$ gross exogenous income

$x=$ disposable income

$f(.,)=$. tax rule that transforms gross incomes $($ wh,m) into net income $x$.

The set B is the opportunity set, i.e. it contains all the opportunities available to the household. For generality we also include non-market opportunities into B; a non-market opportunity is a "job" with $\mathrm{w}=0$ and $\mathrm{h}=0$. Agents can differ not only in their preferences and in their wage (as in the traditional model) but also in the number of available jobs of different type. Note that for the same agent, wage rates (unlike in the traditional model) can differ from job to job. As analysts we do not know exactly what opportunities are contained in $B$. Therefore we use a probability density function to represent $B$. Let us denote by $p(h, w)$ the opportunity density, i.e. the density of jobs of type $(h, w)$. By specifying a probability density function on $B$ we can for example allow for the fact that jobs with hours of work in a certain range are more or less likely to be found, possibly depending on agents' characteristics; or for the fact that for different agents the relative number of market opportunities may 
differ. From expression (A.1) it is clear that what we adopt is a choice model; choice, however, is constrained by the number and the characteristics of jobs in the opportunity set. Therefore the model is also compatible with the case of involuntary unemployment, i.e. an opportunity set that does not contain any market opportunity. Besides this extreme case, the number and the characteristics of market (and non-market) opportunities in general vary from individual to individual. Even if the set of market opportunities is not empty, in some cases it might contain very few elements and/or elements with bad characteristics.

We assume that the utility function can be factorized as

$$
U(f(w h, m), h, j)=v(f(w h, m) \mathcal{E}(h, w, j)
$$

where $\mathrm{v}$ and $\varepsilon$ are the systematic and the stochastic component respectively, and $\varepsilon$ is i.i.d. according to:

$$
\operatorname{Pr}(\varepsilon \leq u)=\exp \left(-u^{-1}\right)
$$

The term $\varepsilon$ is a random taste-shifter which accounts for the effect on utility of all the characteristics of the household-job match which are observed by the household but not by us. We observe the chosen $h$ and $w$. Therefore we can specify the probability that the agent chooses a job with observed characteristics $(h, w)$. It can be shown that under the assumptions (A.1), (A.2) and (A.3) we can write the probability density function of a choice $(h, w)$ as follows ${ }^{12}$ :

$$
\varphi(h, w)=\frac{v(f(w h, I), h) p(h, w)}{\iint v(f(x y, I), y) p(y, x) d x d y}
$$

Expression (A.4) is analogous to the continuous multinomial logit developed in the transportation and location analysis literature. The intuition behind expression (A.4) is that the probability of a choice $(h, w)$ can be expressed as the relative attractiveness - weighted by a measure of "availability" $p(h, w)$ - of jobs of type $(h, w)$. More details on the derivation of (A.4) can be found in Aaberge et al. (1999).

From (A.4) we also see that this approach does not suffer from the complexity of the tax rule $f$. The tax rule, however complex, enters the expression as it is, and there is no need to simplify it in order to make it differentiable or manageable as in the traditional approach. The crucial difference is that in the traditional approach the functions representing household behaviour are derived on the basis

\footnotetext{
${ }^{12}$ For the derivation of the choice density (A.4), see Aaberge et al. (1999)..
} 
of a comparison of marginal variations of utility, while in the approach that we follow a comparison of levels of utility is directly involved.

In order to estimate the model we choose convenient but still flexible parametric forms for $V$ and $p(h, w)$. The parameters are estimated by maximum likelihood. The likelihood function is the product of the choice densities (A.4) for every household in the sample.

\section{A.2. The Data}

The estimation and the simulation of the model is based on data from the 1993 Survey of Household Income and Wealth (SHIW93). This survey is conducted every two years by the Bank of Italy and, besides household and individual socio-demographic characteristics, contains detailed information on labour, income and wealth of each household component. We use the 1993 survey since it is the only one containing information on family background. This information is necessary in order to perform the evaluation of alternative tax-transfer rules according to the EOP criterion.

The sample that we select contains 4827 individuals (2160 couples, 310 single females and 206 single males). Singles and couples with income from self-employment are excluded from the sample: this is because their decision process may be substantially different from wage employees' and typically involves a permanent element of uncertainty.

We have restricted the ages of the individuals to be between 19 and 54 in order to minimize the inclusion in the sample of individuals who in principle are eligible for retirement, since the current version of the model does not take the retirement decision into account.

Due to the above selection rules, the estimates and the simulations should be interpreted as conditional upon the decisions not to be self-employed and not to retire.

The labour incomes measured by the survey are net of social security contributions and of taxes on personal income. Therefore, in order to compute gross incomes we have to apply the "inverse" tax code. In turn, the "direct" tax code has to be applied to every point in each household's choice set to compute disposable income associated with that point. Hourly wage rates are obtained by dividing gross annual wage income by observed hours.

Table A.1 reports the descriptive statistics of the variables used in the microeconometric model. Other statistics on labour supply, incomes and taxes are reported in Table A.2. 
Table A.1. Descriptive statistics of the variables used in the microeconometric model. Italy 1993.

\begin{tabular}{|l|l|c|c|c|c|c|c|c|c|}
\hline & & \multicolumn{4}{|c|}{ Female } & \multicolumn{4}{c|}{ Male } \\
\hline Family status & Variable & Mean & Std. Dev. & Min & Max & Mean & Std. Dev. & Min & Max \\
\hline \multirow{5}{*}{ Single } & A & 40.90 & 8.74 & 19 & 54 & 38.86 & 9.39 & 21 & 54 \\
\cline { 2 - 12 } & S & 9.73 & 4.21 & 0 & 19 & 10.47 & 4.09 & 0 & 19 \\
\cline { 2 - 12 } & CU6 & 0.03 & 0.18 & 0 & 1 & 0 & 0 & 0 & 0 \\
\cline { 2 - 12 } & CO6 & 0.17 & 0.49 & 0 & 4 & 0.03 & 0.22 & 0 & 2 \\
\cline { 2 - 11 } & N & 2.25 & 1.13 & 1 & 13 & 1.99 & 1.08 & 1 & 6 \\
\cline { 2 - 11 } & w & 12.14 & 12.18 & 0 & 144.35 & 14.03 & 8.76 & 0 & 144.79 \\
\cline { 2 - 11 } & h & 1351.57 & 857.80 & 0 & 3328 & 1737.33 & 782.38 & 0 & 3640 \\
\hline \multirow{5}{*}{ Couples } & & & & & & & & & \\
\cline { 2 - 11 } & A & 38.13 & 7.62 & 19 & 54 & 41.33 & 7.47 & 22 & 54 \\
\cline { 2 - 11 } & S & 9.45 & 4.13 & 0 & 19 & 9.76 & 3.96 & 0 & 19 \\
\cline { 2 - 11 } & CO6 & 0.34 & 0.58 & 0 & 3 & CU6 & 0.34 & 0.58 & 0 \\
\cline { 2 - 10 } & N & 0.58 & 0.73 & 0 & 3 & CO6 & 0.58 & 0.73 & 0 \\
\cline { 2 - 10 } & w & 7.78 & 1.04 & 2 & 9 & 3.78 & 1.04 & 2 & 9 \\
\cline { 2 - 10 } & h & 741.95 & 893.13 & 0 & 3640 & 1990.26 & 506.66 & 0 & 3640 \\
\hline
\end{tabular}

Note: $\mathrm{A}=$ age, $\mathrm{S}=$ years of education, CU6 = number of children of age $<6, \mathrm{CO} 6=$ number of children of age $>=6, \mathrm{w}=$ hourly wage rate (1000 ITL 1993), $\mathrm{h}=$ annual hours of work.

Table A.2. Observed participation rates, annual hours of work, gross income, taxes and deciles of household disposable income for single females, single males and couples. Italy 1993.

\begin{tabular}{|c|c|c|c|c|c|c|c|c|c|c|c|c|c|}
\hline \multirow{3}{*}{$\begin{array}{l}\text { Family } \\
\text { status }\end{array}$} & & \multirow{2}{*}{\multicolumn{2}{|c|}{$\begin{array}{l}\text { Participation } \\
\text { rates } \\
\text { (Per cent) }\end{array}$}} & \multicolumn{4}{|c|}{ Annual hours } & \multicolumn{6}{|c|}{ Household income, 1000 ITL 1993} \\
\hline & & & & \multicolumn{2}{|c|}{$\begin{array}{c}\text { Given } \\
\text { participation }\end{array}$} & \multicolumn{2}{|c|}{$\begin{array}{l}\text { In the total } \\
\text { population }\end{array}$} & \multicolumn{2}{|c|}{ Gross income } & \multicolumn{2}{|c|}{ Taxes } & \multicolumn{2}{|c|}{$\begin{array}{l}\text { Disposable } \\
\text { income }\end{array}$} \\
\hline & & F & $\mathrm{M}$ & F & $\mathrm{M}$ & F & M & $\mathrm{F}$ & M & F & M & $\mathrm{F}$ & M \\
\hline \multirow{6}{*}{ Singles } & I & 28 & 64 & 623 & 1496 & 168 & 966 & 4723 & 12307 & 310 & 1455 & 4413 & 10852 \\
\hline & II & 62 & 85 & 1270 & 1811 & 784 & 1540 & 12263 & 21248 & 946 & 3275 & 11318 & 17972 \\
\hline & III & 84 & 90 & 1717 & 1945 & 1442 & 1758 & 33159 & 43570 & 5374 & 8097 & 27785 & 35474 \\
\hline & IV & 93 & 92 & 1847 & 2070 & 1711 & 1893 & 62437 & 75630 & 12820 & 16520 & 49617 & 59110 \\
\hline & $\mathrm{V}$ & 88 & 95 & 1891 & 2124 & 1663 & 2014 & 96571 & 106137 & 21514 & 23859 & 75057 & 82279 \\
\hline & VI & 77 & 88 & 1676 & 1932 & 1298 & 1695 & 37480 & 47707 & 6779 & 9376 & 30702 & 38331 \\
\hline \multirow{6}{*}{ Couples } & I & 14 & 96 & 1030 & 1571 & 145 & 1501 & \multicolumn{2}{|c|}{15221} & \multicolumn{2}{|c|}{525} & \multicolumn{2}{|c|}{14695} \\
\hline & II & 20 & 98 & 1209 & 1832 & 241 & 1787 & \multicolumn{2}{|c|}{24372} & \multicolumn{2}{|c|}{2109} & \multicolumn{2}{|c|}{22263} \\
\hline & III & 44 & 99 & 1546 & 1991 & 677 & 1970 & \multicolumn{2}{|c|}{48187} & \multicolumn{2}{|c|}{8960} & \multicolumn{2}{|c|}{39227} \\
\hline & IV & 66 & 99 & 1731 & 2117 & 1133 & 2103 & \multicolumn{2}{|c|}{85135} & \multicolumn{2}{|c|}{19983} & \multicolumn{2}{|c|}{65152} \\
\hline & $\mathrm{V}$ & 74 & 99 & 1828 & 2237 & 1361 & 2225 & \multicolumn{2}{|c|}{128396} & \multicolumn{2}{|c|}{34365} & \multicolumn{2}{|c|}{94032} \\
\hline & VI & 44 & 98 & 1590 & 1972 & 694 & 1943 & \multicolumn{2}{|c|}{54225} & \multicolumn{2}{|c|}{11074} & \multicolumn{2}{|c|}{43150} \\
\hline
\end{tabular}

Note: I = first decile; II = second decile; III = third to eighth deciles; IV = ninth decile; $\mathrm{V}=$ tenth decile; $\mathrm{VI}=$ whole sample. 
Table A.3 shows the marginal tax schedule applied to personal incomes in 1993. The unit of taxation is the individual.

Table A.3. Marginal tax rates applied to personal incomes. Italy 1993.

\begin{tabular}{|l|c|}
\hline Income $(1000$ LIT) & Marginal tax rate (per cent) \\
\hline Up to 7,200 & 10 \\
$7,200-14,400$ & 22 \\
$14,400-30,000$ & 27 \\
$30,000-60,000$ & 34 \\
$60,000-150,000$ & 41 \\
$150,000-300,000$ & 46 \\
Over 300,000 & 51 \\
\hline
\end{tabular}

Some expenditures (such as medical or insurance) can be deducted from income before applying taxes. Child allowances and dependent spouse allowances - up to the amount of the gross tax - can be subtracted from the tax. Conditional on the number of household members and household total income, the head of the household may receive family benefits.

\section{A.3. Empirical specification}

To account for the fact that single individuals and married couples may face different choice sets and exhibit different preferences over income and leisure we estimate separate models for single females and males and married couples. Hereafter we explain the empirical specification chosen for the utility functions and the opportunity density functions. Tables A.4 and A.5 will present the Maximum Likelihood parameter estimates. Table A.6 will illustrate the wage elasticities of labour supply implied by the estimates and obtained by microsimulation.

\section{A.3.1. Singles}

The structural part of the utility functions for single females and males is assumed to be of the following form

(A.5) $\log v(f(w h, I), h)=\left(\alpha_{2}+\alpha_{3} N\right)\left(\frac{f(w h, I)^{\alpha_{1}}-1}{\alpha_{1}}\right)+\left(\alpha_{5}+\alpha_{6} \log A+\alpha_{7}(\log A)^{2}+\alpha_{8} C U 6+\alpha_{9} C O 6\right)\left(\frac{L^{\alpha_{4}}-1}{\alpha_{4}}\right)$ where $f(w h, I)$ is disposable income (income after tax) measured in $10^{7} \mathrm{JTL}, N$ is the size of the household, $A$ is age, $C U 6$ and $C O 6$ are number of children below and above 6 years old and $L$ is the 
proportion of leisure time relative to total available time, i.e. $L=1-(h / 8736)$. Note that the children terms are dropped in the utility function for single males.

We assume that the density of pairs of offered hours and wages in the market is given by

$$
p(h, w)=\left\{\begin{array}{ccc}
p_{0} g_{1}(h) g_{2}(w) & \text { if } & h>0 \\
1-p_{0} & \text { if } & h=0
\end{array}\right.
$$

where $p_{0}$ is the proportion of market opportunities in the opportunity set, and $g_{1}$ and $g_{2}$ are the densities of hours and wages, respectively. Hours is assumed to be uniformly distributed except for a possible peak in the full-time job interval $<1846,2106>$. Thus, $g_{1}$ is given by

$$
g_{1}(h)=\left\{\begin{array}{ccc}
\gamma & \text { if } & h \in[52,1846] \\
\gamma \pi & \text { if } & h \in\langle 1846,2106\rangle \\
\gamma & \text { if } & h \in[2106,3640]
\end{array}\right.
$$

where 3640 is the maximum hours observed in the sample and

$$
\gamma=\frac{1}{3380+260 \pi}
$$

The proportion of market opportunities $\left(p_{0}\right)$ is assumed to depend on whether one lives in northern or southern Italy,

$$
p_{0}=\frac{1}{1+\exp \left(-\mu_{0}-\mu_{1} R\right)}
$$

where $R=1$ if the individual is living in North-Italy. Thus, a positive value for $\mu_{1}$ means that living in North-Italy increases the proportion of market opportunities in the opportunity set.

The density of offered wages is assumed to be lognormal with mean that depends on length of schooling $(S)$ and on past potential working experience $(E)$, where experience is defined to be equal to age minus length of schooling minus five,

$$
\log w=\beta_{0}+\beta_{1} S+\beta_{2} E+\beta_{3} E^{2}+\eta
$$

where $\eta$ is standard normally distributed.

Given the above assumption upon the stochastic component and upon the density of opportunities, it turns out that the probability (density) that an opportunity $(h, w)$ is chosen is 
(A.11)

$$
\varphi(h, w)=\frac{v(f(w h, I), h) p(h, w)}{\iint v(f(x y, I), y) p(y, x) d x d y}
$$

In view of the empirical specification it is convenient to divide both numerator and denominator by $1-p_{0}$ and define $g_{0}=\frac{p_{0}}{1-p_{0}}=\exp \left(\mu_{0}+\mu_{1} R\right)$. We can then rewrite the choice density as follows:

(A.12)

$$
\varphi(h, w)=\frac{v(f(w h, I), h) g_{0} g_{1}(h) g_{2}(w)}{v(f(0, I), 0)+\int_{x>0} \int_{y>0} v(f(x y, I), y) g_{0} g_{1}(y) g_{2}(x) d x d y}
$$

for $\{h, w\}>0$ and

(A.13)

$$
\varphi(0,0)=\frac{v(f(0, I), 0)}{v(f(0, I), 0)+\int_{x>0} \int_{y>0} v(f(x y, I), y) g_{0} g_{1}(y) g_{2}(x) d x d y}
$$

for $\{h, w\}=0$. 
Table A.4. Estimates of the parameters of the utility functions and the opportunity densities for single females and males ${ }^{*}$. Italy 1993

\begin{tabular}{|c|c|c|c|}
\hline Variable & Coefficient & Single females & Single males \\
\hline \multicolumn{4}{|l|}{ Preferences: } \\
\hline \multirow[t]{3}{*}{ Consumption } & $\alpha_{1}$ & $0.347 \quad(0.163)$ & $0.274 \quad(0.208)$ \\
\hline & $\alpha_{2}$ & $0.951 \quad(0.248)$ & $1.268 \quad(0.359)$ \\
\hline & $\alpha_{3}$ & $-0.232 \quad(0.087)$ & $-0.048 \quad(0.165)$ \\
\hline \multirow[t]{6}{*}{ Leisure } & $\alpha_{4}$ & $-14.401 \quad(6.778)$ & $-12.185 \quad(4.391)$ \\
\hline & $\alpha_{5}$ & $7.377(11.020)$ & $0.622 \quad(5.112)$ \\
\hline & $\alpha_{6}$ & $-3.925 \quad(5.904)$ & $-0.251 \quad(2.754)$ \\
\hline & $\alpha_{7}$ & $0.527 \quad(0.800)$ & $0.027 \quad(0.375)$ \\
\hline & $\alpha_{8}$ & $0.185 \quad(0.314)$ & \\
\hline & $\alpha_{9}$ & $-0.022 \quad(0.044)$ & \\
\hline \multicolumn{4}{|l|}{ Opportunities: } \\
\hline \multirow[t]{2}{*}{ Market opportunities } & $\mu_{0}$ & $-0.697 \quad(0.268)$ & $-2.063 \quad(0.408)$ \\
\hline & $\mu_{1}$ & $0.207 \quad(0.295)$ & $0.360 \quad(0.476)$ \\
\hline Hours density (peak) & $\pi$ & $10.990 \quad(4.299)$ & $17.993 \quad(7.718)$ \\
\hline \multirow[t]{5}{*}{ Wage density } & $\beta_{0}$ & $1-012 \quad(0.194)$ & $0.987 \quad(0.184)$ \\
\hline & $\beta_{1}$ & $0.092(0.009)$ & $0.081 \quad(0.009)$ \\
\hline & $\beta_{2}$ & $0.029 \quad(0.013)$ & $0.041 \quad(0.012)$ \\
\hline & $\beta_{3}$ & $-0.253 \cdot 10^{-3}\left(0.266 \cdot 10^{-3}\right.$ & $-0.425 \cdot 10^{-3}\left(0.248 \cdot 10^{-3}\right.$ \\
\hline & $\sigma^{2}$ & $0.423 \quad(0,018)$ & $0.385 \quad(0.021)$ \\
\hline
\end{tabular}

\footnotetext{
${ }^{*}$ Standard deviations in parentheses.
} 


\subsubsection{Married couples}

The labour supply model for married couples accounts for both spouses' decisions through the following specification of the structural part of the utility function for couples:

$$
\begin{aligned}
& \log v(f(w h, I), h)=\left(\alpha_{2}+\alpha_{3} N\right)\left(\frac{f(w h, I)^{\alpha_{1}}-1}{\alpha_{1}}\right)+\left(\alpha_{5}+\alpha_{6} \log A_{M}+\alpha_{7}(\log A)^{2}\right)\left(\frac{L_{M}^{\alpha_{4}}-1}{\alpha_{4}}\right) \\
& +\left(\alpha_{9}+\alpha_{10} \log A_{F}+\alpha_{11}\left(\log A_{F}\right)^{2}+\alpha_{12} C U 6+\alpha_{13} C O 6\right)\left(\frac{L_{F}^{\alpha_{8}}-1}{\alpha_{8}}\right) .
\end{aligned}
$$

We allow for gender-specific job opportunities in accordance with the functional forms ((3.2)-(3.6)) that were used for single females and males. The estimates of the model parameters for couples have previously been reported in Aaberge et al. (2000).

In this case the households choose among opportunities defined by a vector $\left(h_{M}, h_{F}, w_{M}, w_{F}\right)$.

Analogously to what we have done with singles, we specify the corresponding density function as

$$
p\left(h_{M}, h_{F}, w_{M}, w_{F}\right)=\left\{\begin{array}{l}
p_{0 M} g_{1 M}\left(h_{M}\right) g_{2 M}\left(w_{M}\right) p_{0 F} g_{1 F}\left(h_{F}\right) g_{2 F}\left(w_{F}\right) \text { if } h_{M}>0, h_{F}>0 \\
p_{0 M} g_{1 M}\left(h_{M}\right) g_{2 M}\left(w_{M}\right)\left(1-p_{0 F}\right) \text { if } h_{M}>0, h_{F}=0 \\
\left(1-p_{0 M}\right) p_{0 F} g_{1 F}\left(h_{F}\right) g_{2 F}\left(w_{F}\right) \text { if } h_{M}=0, h_{F}>0 \\
\left(1-p_{0 M}\right)\left(1-p_{0 F}\right) \text { if } h_{M}=0, h_{F}>0
\end{array}\right.
$$

where

$$
\begin{aligned}
& p_{0 M}=\frac{1}{1+\exp \left(-\mu_{0 M}-\mu_{1 M} R\right)} \\
& p_{0 F}=\frac{1}{1+\exp \left(-\mu_{0 F}-\mu_{1 F} R\right)}
\end{aligned}
$$

are the proportions of opportunities that are market jobs for the husband (M) or, respectively, for the wife $(\mathrm{F})$.

The choice density of an opportunity $\left(h_{M}, h_{F}, w_{M}, w_{F}\right)$ is:

$$
\varphi=\frac{v\left(f\left(w_{M} h_{M}, w_{F} h_{F}, I\right), h_{M}, h_{F}\right) p\left(h_{M}, h_{F}, w_{M}, w_{F}\right)}{\iiint \int v\left(f\left(x_{M} y_{M}, x_{F} y_{F}, I\right), y_{M}, y_{F}\right) p\left(y_{M}, y_{F}, x_{M}, x_{F}\right) d x_{F} d y_{F} d x_{M} d y_{M}}
$$


For the purpose of empirical specification and estimation it is convenient to divide the density $p()$ by $\left(1-p_{0 M}\right)\left(1-p_{0 F}\right)$ and define

(A.18)

$$
\begin{aligned}
g_{0 M} & =\frac{p_{0 M}}{\left(1-p_{0 M}\right)} \\
g_{0 F} & =\frac{p_{0 F}}{\left(1-p_{0 F}\right)} \\
g_{0 M F} & =\frac{p_{0 M} p_{0 F}}{\left(1-p_{0 M}\right)\left(1-p_{0 F}\right)}
\end{aligned}
$$

Now the choice density can be written as follows:

(A.19) $\varphi=\frac{v\left(f\left(w_{M} h_{M}, w_{F} h_{F}, I\right), h_{M}, h_{F}\right) g_{0 M F} g_{1 M}\left(h_{M}\right) g_{2 M}\left(w_{M}\right) g_{1 F}\left(h_{F}\right) g_{2 F}\left(w_{F}\right)}{D}$

if both work;

$$
\varphi=\frac{v\left(f\left(w_{M} h_{M}, 0, I\right), h_{M}, 0\right) g_{0 M} g_{1 M}\left(h_{M}\right) g_{2 M}\left(w_{M}\right)}{D}
$$

if only the husband works;

$$
\varphi=\frac{v\left(f\left(0, w_{F} h_{F}, I\right), 0, h_{F}\right) g_{0 F} g_{1 F}\left(h_{F}\right) g_{2 F}\left(w_{F}\right)}{D}
$$

if only the wife works;

$$
\varphi=\frac{v(f(0,0, I), 0,0)}{D}
$$

if none of them works.

The denominator $\mathrm{D}$ is defined as follows: 


$$
D=v(f(0,0, I), 0,0)+\iint_{\substack{x>0 \\ y>0}} v\left(f\left(x_{M} y_{M}, 0, I\right), y_{M}, 0\right) g_{0 M} g_{1 M}\left(y_{M}\right) g_{2 M}\left(x_{M}\right) d x_{M} d y_{M}
$$

(A.23) $\iint_{\substack{x>0 \\ y>0}} v\left(f\left(0, x_{F} y_{F}, I\right), 0, y_{F}\right) g_{0 F} g_{1 F}\left(y_{F}\right) g_{2 F}\left(x_{F}\right) d x_{F} d y_{F}+$

$$
\iiint_{\substack{x>0 \\ y>0}} v\left(f\left(x_{M} y_{M}, x_{F} y_{F}, I\right), y_{M}, y_{F}\right) g_{0 M F} g_{1 M}\left(y_{M}\right) g_{2 M}\left(x_{M}\right) p_{0 F} g_{1 F}\left(y_{F}\right) g_{2 F}\left(x_{F}\right) d x_{M} d y_{F} d x_{M} d y_{M}
$$


Table A.5.Estimates of the parameters of the utility function and the opportunity densities for married couples. ${ }^{*)}$ Italy 1993

\begin{tabular}{|c|c|c|}
\hline Variable & Coefficient & Estimates \\
\hline \multicolumn{3}{|l|}{ Preferences: } \\
\hline \multirow[t]{3}{*}{ Consumption } & $\alpha_{1}$ & $0.728 \quad(0.057)$ \\
\hline & $\alpha_{2}$ & $1.476 \quad(0.174)$ \\
\hline & $\alpha_{3}$ & $-0.103 \quad(0.028)$ \\
\hline \multirow[t]{4}{*}{ Husband's leisure } & $\alpha_{4}$ & $-12.763 \quad(0.869)$ \\
\hline & $\alpha_{5}$ & $-1.408 \quad(1.122)$ \\
\hline & $\alpha_{6}$ & $0.760 \quad(0.622)$ \\
\hline & $\alpha_{7}$ & $-0.097 \quad(0.085)$ \\
\hline \multirow[t]{6}{*}{ Wife's leisure } & $\alpha_{8}$ & $-8.012 \quad(0.778)$ \\
\hline & $\alpha_{9}$ & 74.509 (22.923) \\
\hline & $\alpha_{10}$ & $-41.608 \quad(12.797)$ \\
\hline & $\alpha_{11}$ & $5.881 \quad(1.794)$ \\
\hline & $\alpha_{12}$ & $0.302 \quad(0.127)$ \\
\hline & $\alpha_{13}$ & $0.277 \quad(0.105)$ \\
\hline \multicolumn{3}{|l|}{ Opportunities: } \\
\hline \multicolumn{3}{|c|}{ Market opportunities } \\
\hline \multirow[t]{2}{*}{ Husband } & $\mu_{0 \mathrm{M}}$ & $-2.412 \quad(0.222)$ \\
\hline & $\mu_{1 \mathrm{M}}$ & $1.821 \quad(0.623)$ \\
\hline \multirow[t]{2}{*}{ Wife } & $\mu_{0 \mathrm{~F}}$ & $-0.796 \quad(0.095)$ \\
\hline & $\mu_{1 \mathrm{~F}}$ & $0.631 \quad(0.102)$ \\
\hline \multicolumn{3}{|c|}{ Hours densities (peak) } \\
\hline Husband & $\pi_{\mathrm{M}}$ & $14.453 \quad(3.328)$ \\
\hline Wife & $\pi_{\mathrm{F}}$ & $11.670 \quad(3.504)$ \\
\hline \multicolumn{3}{|l|}{ Wage densities } \\
\hline \multirow[t]{5}{*}{ Husband } & $\beta_{0 \mathrm{M}}$ & $1.212(0.080)$ \\
\hline & $\beta_{1 \mathrm{M}}$ & $0.074 \quad(0.003)$ \\
\hline & $\beta_{2 \mathrm{M}}$ & $0.024 \quad(0.005)$ \\
\hline & $\beta_{3 \mathrm{M}}$ & $-0.154 \cdot 10^{-3}\left(0.100 \cdot 10^{-3}\right)$ \\
\hline & $\sigma_{\mathrm{M}}^{2}$ & $0.391 \quad(0.006)$ \\
\hline \multirow[t]{5}{*}{ Wife } & $\beta_{0 \mathrm{~F}}$ & $0.888 \quad(0.102)$ \\
\hline & $\beta_{1 F}$ & $0.101 \quad(0.004)$ \\
\hline & $\beta_{2 \mathrm{~F}}$ & $0.027 \quad(0.008)$ \\
\hline & $\beta_{3 \mathrm{~F}}$ & $-0.224 \cdot 10^{-3}\left(0.163 \cdot 10^{-3}\right)$ \\
\hline & $\sigma_{\mathrm{F}}^{2}$ & $0.377 \quad(0.009)$ \\
\hline
\end{tabular}

*) Standard deviations in parentheses. 
Table A.6. Labour supply elasticities for single females, single males, married females and married males by deciles of household disposable income. Italy 1993.

\begin{tabular}{|c|c|c|c|c|c|c|}
\hline \multirow[b]{2}{*}{ Family status } & \multirow[b]{2}{*}{$\begin{array}{l}\text { Type of } \\
\text { elasticity }\end{array}$} & \multirow{2}{*}{$\begin{array}{l}\text { Decile of } \\
\text { income } \\
\text { distribution }\end{array}$} & \multicolumn{2}{|c|}{ Female elasticities } & \multicolumn{2}{|c|}{ Male elasticities } \\
\hline & & & $\begin{array}{l}\text { Own wage } \\
\text { elasticities }\end{array}$ & $\begin{array}{c}\text { Cross } \\
\text { elasticities }\end{array}$ & $\begin{array}{l}\text { Own wage } \\
\text { elasticities }\end{array}$ & $\begin{array}{c}\text { Cross } \\
\text { elasticities }\end{array}$ \\
\hline \multirow{15}{*}{ Singles } & \multirow{5}{*}{$\begin{array}{l}\text { Elasticity of the } \\
\text { probability of } \\
\text { participation }\end{array}$} & I & 0.71 & & 0.52 & \\
\hline & & II & 0.22 & & 0.18 & \\
\hline & & III & 0.03 & & 0.03 & \\
\hline & & IV & 0.00 & & 0.05 & \\
\hline & & $\mathrm{V}$ & 0.00 & & 0.05 & \\
\hline & \multirow{5}{*}{$\begin{array}{l}\text { Elasticity of the } \\
\text { conditional } \\
\text { expectation of } \\
\text { total supply of } \\
\text { hours }\end{array}$} & I & 1.81 & & 0.28 & \\
\hline & & II & 0.24 & & 0.11 & \\
\hline & & III & 0.03 & & 0.02 & \\
\hline & & IV & 0.02 & & -0.02 & \\
\hline & & $\mathrm{V}$ & 0.00 & & -0.01 & \\
\hline & \multirow{5}{*}{$\begin{array}{l}\text { Elasticity of the } \\
\text { unconditional } \\
\text { expectation of } \\
\text { total supply of } \\
\text { hours }\end{array}$} & I & 2.90 & & 0.85 & \\
\hline & & II & 0.44 & & 0.28 & \\
\hline & & III & 0.05 & & 0.05 & \\
\hline & & IV & 0.02 & & 0.02 & \\
\hline & & $\mathrm{V}$ & 0.00 & & 0.04 & \\
\hline \multirow{15}{*}{ Couples } & \multirow{5}{*}{$\begin{array}{l}\text { Elasticity of the } \\
\text { probability of } \\
\text { participation }\end{array}$} & I & 2.40 & 0.26 & 0.04 & -0.02 \\
\hline & & II & 1.35 & -0.19 & 0.05 & -0.02 \\
\hline & & III & 0.54 & -0.18 & 0.01 & -0.01 \\
\hline & & IV & 0.16 & -0.16 & 0.02 & -0.01 \\
\hline & & $\mathrm{V}$ & 0.10 & -0.15 & 0.02 & 0.00 \\
\hline & \multirow{5}{*}{$\begin{array}{l}\text { Elasticity of the } \\
\text { conditional } \\
\text { expectation of } \\
\text { total supply of } \\
\text { hours }\end{array}$} & I & 1.60 & 0.55 & 0.28 & 0.08 \\
\hline & & II & 0.83 & 0.05 & 0.12 & 0.02 \\
\hline & & III & 0.18 & -0.06 & 0.08 & -0.02 \\
\hline & & IV & 0.04 & -0.04 & 0.06 & -0.02 \\
\hline & & $\mathrm{V}$ & 0.04 & -0.02 & 0.04 & -0.02 \\
\hline & \multirow{5}{*}{$\begin{array}{l}\text { Elasticity of the } \\
\text { unconditional } \\
\text { expectation of } \\
\text { total supply of } \\
\text { hours }\end{array}$} & $\mathrm{I}$ & 4.44 & 0.82 & 0.32 & 0.06 \\
\hline & & II & 2.31 & -0.15 & 0.17 & 0.00 \\
\hline & & III & 0.73 & -0.24 & 0.10 & -0.04 \\
\hline & & IV & 0.20 & -0.20 & 0.08 & -0.03 \\
\hline & & $\mathrm{V}$ & 0.13 & -0.17 & 0.06 & -0.02 \\
\hline
\end{tabular}

Note: $\mathrm{I}=$ first decile; $\mathrm{II}=$ second decile; $\mathrm{III}=$ third to eighth deciles; $\mathrm{IV}=$ ninth decile; $\mathrm{V}=$ tenth decile. 


\section{References}

Aaberge, R. (2000): Characterizations of Lorenz Curves and Income Distributions, Social Choice and Welfare 17, 639-653.

Aaberge, R. (2001): Axiomatic Characterization of the Gini Coefficient and Lorenz Curve Orderings, Journal of Economic Theory 101, 115-132.

Aaberge, R. (2007): Gini's Nuclear Family, Journal of Economic Inequality 5, 305-322, 2007.

Aaberge, R., Colombino, U. and S. Strøm (1999): Labour Supply in Italy: An Empirical Analysis of Joint Household Decisions, with Taxes and Quantity Constraints, Journal of Applied Econometrics, $14,403-422$.

Aaberge, R. And U. Colombino (2008): Designing Optimal Taxes with a Microeconometric Model of Household Labour Supply, WP CHILD n. 06/2008 (www.child-centre.it).

Arneson, R. (1989): Equality and Equality of Opportunity for Welfare, Philosophical Studies 56, 7793.

Arneson, R. (1990): Liberalism, Distributive Subjectivism, and Equal Opportunity for Welfare, Philosophy \& Public Affairs 19, 159-94

Behrman, J et al. (1999): Women's Schooling, Home Teaching and Economic Growth, Journal of Political Economy 107, 682-714.

Ben Porath, E. and I. Gilboa (1994): Linear Measures, the Gini Index, and the Income-Equality Tradeoff, Journal of Economic Theory 64, 443-467.

Bonferroni, C. (1930): Elementi di Statistica Generale. Seeber, Firenze.

Bossert, W. (1990): An Approximation of the Single-series Ginis, Journal of Economic Theory 50, 8292.

Bourguignon, F., F. Ferreira, and M. Menéndez (2003): Inequality of Outcomes and Inequality of Opportunities in Brazil, World Bank Policy Research Papers 3174.

Checchi, D. and V. Peragine (2009): Regional Disparities and Inequality of Opportunity: The Case of Italy, Jornal of Economic Inequality, DOI 10.1007/s10888-009-9118-3.

Cohen, G.A. (1989): On the Currency of Egalitarian Justice, Ethics 99, 906-44

Dagsvik, J.K. (1994): Discrete and Continuous Choice, Max-Stable Processes and Independence from Irrelevant Attributes, Econometrica 62, 1179-1205.

Donaldson, D. and J.A. Weymark (1980): A Single Parameter Generalization of the Gini Indices of Inequality, Journal of Economic Theory 22, 67-86. 
Donaldson, D. and J.A. Weymark (1983): Ethically flexible Indices for Income Distributions in the Continuum, Journal of Economic Theory 29, 353-358.

Dustmann, C. (2004): Parental Background, Secondary School Track Choice, and Wages, Oxford Economic Papers 56 (2004), 209-230.

Dworkin, R. (1981a): What is Equality? Part 1: Equality of Welfare, Philosophy \& Public Affairs 10, 185-246.

Dworkin, R. (1981b): What is Equality? Part 2: Equality of Resources, Philosophy \& Public Affairs 10, 283-345b.

Ermisch, J. and M. Francesconi (2001): Family Mattaers: Impact of Family Background on Educational Attainment, Economica 68, 137-156.

Hey, J.D. and P.J. Lambert (1980): Relative Deprivation and the Gini Coefficient: Comment, Quarterly Journal of Economics 94, 567-573.

Mehran, F. (1976): Linear Measures of Inequality, Econometrica 44, 805-809.

Peragine, V. (2002): Opportunity egalitarianism and income inequality: the rank-dependent approach, Mathematical Social Sciences 44, 45-64.

Peragine, V. (2004): Measuring and implementing equality of opportunity for income, Social Choice and Welfare 22, 1-24.

Roemer, J (1993): A Pragmatic Theory of Responsibility for the Egalitarian Planner, Philosophy \& Public Affairs 10, 146-166.

Roemer, J (1998): Equality of Opportunity, Harvard University Press.

Roemer, J. E., Aaberge, R., Colombino, U., Fritzell, J., Jenkins, S. P., Lefranc, A., Marx, I., Page, M., Pommer, E. and J. Ruiz-Castillo (2003): To what Extent Do Fiscal Regimes Equalize Opportunities for Income Acquisition among Citizens?, Journal of Public Economics 87, 539-565, 2003.

Sacerdote, B. (2002): The Nature and Nurture of Economic Outcoms, America Economic Review (Papers and Proceedings) 102, 344-348.

Sen, A. (1974): Informational Bases of alternative Welfare Approaches, Journal of Public Economics 3, 387-403.

Weymark, J. (1981): Generalised Gini Inequality Indices, Mathematical Social Sciences 1, 409-430.

Yaari, M.E. (1988): A controversial Proposal Concerning Inequality Measurement, Journal of Economic Theory 44, 381-397. 